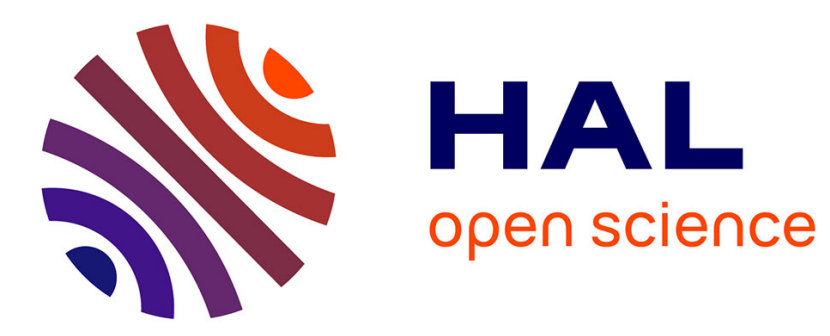

\title{
Melting diagrams of Fe-rich alloys determined from synchrotron in-situ measurements in the 15-23GPa pressure range
}

Denis Andrault, Nathalie Bolfan-Casanova, O. Ohtaka, H. Fukui, H. Arima, M. Fialin, K. Funakoshi

\section{To cite this version:}

Denis Andrault, Nathalie Bolfan-Casanova, O. Ohtaka, H. Fukui, H. Arima, et al.. Melting diagrams of Fe-rich alloys determined from synchrotron in-situ measurements in the 15-23GPa pressure range. Physics of the Earth and Planetary Interiors, 2009, 174 (1-4), pp.181. 10.1016/j.pepi.2008.09.020 . hal-00533033

\section{HAL Id: hal-00533033 \\ https://hal.science/hal-00533033}

Submitted on 5 Nov 2010

HAL is a multi-disciplinary open access archive for the deposit and dissemination of scientific research documents, whether they are published or not. The documents may come from teaching and research institutions in France or abroad, or from public or private research centers.
L'archive ouverte pluridisciplinaire $\mathbf{H A L}$, est destinée au dépôt et à la diffusion de documents scientifiques de niveau recherche, publiés ou non, émanant des établissements d'enseignement et de recherche français ou étrangers, des laboratoires publics ou privés. 


\section{Accepted Manuscript}

Title: Melting diagrams of Fe-rich alloys determined from

synchrotron in-situ measurements in the 15-23 GPa pressure range

Authors: D. Andrault, N. Bolfan-Casanova, O. Ohtaka, H.

Fukui, H. Arima, M. Fialin, K. Funakoshi

PII:

S0031-9201(08)00275-6

DOI: doi:10.1016/j.pepi.2008.09.020

Reference: PEPI 5075

To appear in: Physics of the Earth and Planetary Interiors

Received date: $18-1-2008$

Revised date: $3-9-2008$

Accepted date: 21-9-2008

Please cite this article as: Andrault, D., Bolfan-Casanova, N., Ohtaka, O., Fukui, H., Arima, H., Fialin, M., Funakoshi, K., Melting diagrams of Fe-rich alloys determined from synchrotron in-situ measurements in the 15-23 GPa pressure range, Physics of the Earth and Planetary Interiors (2008), doi:10.1016/j.pepi.2008.09.020

This is a PDF file of an unedited manuscript that has been accepted for publication. As a service to our customers we are providing this early version of the manuscript. The manuscript will undergo copyediting, typesetting, and review of the resulting proof before it is published in its final form. Please note that during the production process errors may be discovered which could affect the content, and all legal disclaimers that apply to the journal pertain. 


\title{
Melting diagrams of Fe-rich alloys determined from synchrotron in-situ measurements in the 15-23 GPa pressure range
}

\author{
D. Andrault ${ }^{a}$, N. Bolfan-Casanova ${ }^{a}$, O. Ohtaka ${ }^{b}$, H. Fukui ${ }^{\text {bcc }}$, \\ H. Arima ${ }^{\text {b }}$, M. Fialin ${ }^{\mathrm{d}}$, K. Funakoshi ${ }^{\mathrm{c}}$ \\ ${ }^{a}$ Laboratoire Magmas et Volcans, Université de Clermont-Ferrand, France \\ ${ }^{b}$ Earth and Space Science, Osaka University, Japan \\ c Japan Synchrotron Radiation Institute, SPring-8, Hyogo, Japan \\ ${ }^{d}$ Centre de microanalyse Camparis, Paris, France
}

\section{Abstract}

We report in situ observations of the melting behaviour of iron alloyed with 10 to 20 atom\% $\mathrm{C}, \mathrm{O}, \mathrm{S}$, or $\mathrm{Si}$ at pressures between 15 and $24 \mathrm{GPa}$, using X-ray diffraction in a multi-anvil press (SPring8). The degree of partial melting of the iron-alloys has been quantified from analysis of the intensity of diffuse $\mathrm{x}$-ray scattering of molten iron as a function for decreasing temperature with a 50 degrees step. Coupled with microanalysis of recovered samples, the insitu observations bring direct constraints on shape and positions of liquidus and solidus in the melting diagrams.

For the Fe-S system, our results are in good agreement with previous works. We observe that the eutectic temperature increases from $1023 \mathrm{~K}$ at $15 \mathrm{GPa}$ to $1123 \mathrm{~K}$ at $20.6 \mathrm{GPa}$ and that the eutectic composition decreases with increases pressure. Concerning the Fe-C system the eutectic temperature of $1460 \mathrm{~K}$ at $20.7 \mathrm{GPa}$ falls slightly below a linear extrapolation of the previous work. In the case of the Fe-Ni-Si system and the Fe-O system, we find eutectic temperatures significantly lower than previously reported. For the two systems, both eutectic temperature and composition increase with increasing pressure in the 15-20 GPa range. Compare to previous work, we observe eutectic compositions (a) richer in light elements in the Fe-O system, with 9.0 and $10.5 \mathrm{wt} \% \mathrm{O}$ at 16.5 and $20.5 \mathrm{GPa}$, respectively, and (b) poorer in the Fe-Ni-Si system with $11.5 \mathrm{wt} \% \mathrm{Si}$ at $16.9 \mathrm{GPa}$.

We confirm very high solubility of $\mathrm{Si}$ and $\mathrm{C}$ with solid iron, and report a Si partitioning coefficient of 1.3(2) at $16.9 \mathrm{GPa}$. The $\mathrm{S}$ and $\mathrm{O}$ solubility in solid iron appears very small. Therefore, both $\mathrm{S}$ and/or O could explain density jumps between liquid outer and solid inner parts of planetary cores, at least up to $\sim 25 \mathrm{GPa}$. 


\section{Introduction}

Iron is the dominant component in planetary cores. It is believed to be alloyed with $5-10 \mathrm{wt} \%$ $\mathrm{Ni}$ and to contain light elements such as $\mathrm{S}, \mathrm{Si}, \mathrm{O}, \mathrm{C}$ and/or $\mathrm{H}$. The presence of nickel, suggested by geochemical arguments and observation of iron meteorites (McDonough and Sun, 1995) is thought to have negligible effects on the properties of iron (Mao et al., 1990). Not much quantitative information is known for planetary cores due to lack of seismological data on most of the planets. In the best case, size and density distribution could be derived from astronomical relations. It is usually assumed that the general picture is not very different from that of the Earth's core, which is itself well sampled thanks to the seismic activity. Until now, the best approach is theoretical modelling of the planetary cores, which clearly requires precise determination of thermodynamical data sets and phase diagrams of the Fe-alloys.

For the Earth's core, the presence of light elements is required to reduce the density of pure iron by $\sim 8-10 \%$ in order to match the actual densities provided by seismological studies (Anderson and Ahrens, 1994; Birch, 1964; Mao et al., 1990). Still, the effect of each potential light element on the iron properties at the highest pressures and temperatures representative of the core remains unclear and therefore various Fe-alloys could easily explain the core density deficit (Poirier, 1994). Another dominant geophysical observation is the density contrast of $\sim 4-6 \%$ at the boundary between inner and outer core (ICB), a density contrast significantly too high to be explained solely by the change in volume upon iron melting, which is estimated to be $\sim 2 \%$ (Alfè et al., 2003). This observation points out to chemical partitioning during the inner core crystallization, with rejection of some of the light elements to the outer core. Geochemical budgets suggest an Earth's core with 7wt\% Si (Allègre et al., 1995; Javoy, 1995). However, a high Si content in the core does not help to explain the density contrast at the ICB, because Si shows very similar partitioning between liquid and solid iron (Alfè et al., 2003). A similar behaviour is expected for carbon (Wood, 1993). Therefore, the presence of significant amounts of $\mathrm{S}$ and/or $\mathrm{O}$ is required to match the density difference at the ICB. On the other hand, experimental studies performed in large volume presses evidence a major role of the oxygen fugacity on the chemical composition of liquid iron, especially the mutual exclusion of Si and O (Gessmann et al., 2001; Malavergne et al., 2004), of Si and S (Kilburn and Wood, 1997) and the relatively good association between S and O (Hillgren et al., 2000; O'Neill et al., 1998). At high concentration, mutual exclusion can yield to immiscible (Fe-S, Fe-O, Fe-Si) liquids (Sanloup et al., 2002; Tsuno et al., 2007). However, recent diamond anvil cell studies up to megabar pressures and much higher temperatures up to $3150 \mathrm{~K}$ show an 
increase in solubility of both $\mathrm{Si}$ and $\mathrm{O}$ in liquid iron, possibly as a $\mathrm{FeSiO}_{3}$ component (Sakai et al., 2006; Takafuji et al., 2005).

At ambient pressure, well-known phase diagrams show large compositional ranges for $\mathrm{Fe}$ liquids alloyed with various light elements. In the solid state, solid solutions also exist for light element concentrations up to $\sim 20 \mathrm{wt} \% \mathrm{Si}$ and $\sim 2 \mathrm{wt} \% \mathrm{C}$, while $\mathrm{S}$ and $\mathrm{O}$ are largely incompatible with the solid iron lattice. Ab-initio calculations suggests that $\mathrm{S}$ becomes increasingly compatible with solid iron as pressure increases, while $\mathrm{O}$ remains incompatible with solid iron up to ICB pressures (Alfè et al., 2003; Boness and Brown, 1990). This remains to be confirmed experimentally, because it could be controversial at least for the case of $\mathrm{S}$ (Morard et al., 2007). Concerning eutectic temperatures, the general trend appears to be $\mathrm{dT} / \mathrm{dP}$ Clapeyron slopes smaller compared to the melting curve of pure iron (Fei et al., 1997; Hirayama et al., 1993; Ohtani et al., 1984; Urakawa et al., 1987). The special case is for the Fe-S system in which eutectic temperatures have been reported to decrease with increasing pressure up to $\sim 17 \mathrm{GPa}$ (Fei et al., 2000). Whereas recent works performed at higher pressure in this system show an increase of eutectic temperature at higher pressures (Campbell et al., 2007; Chudinovskikh and Boehler, 2007; Morard et al., 2007; Stewart et al., 2008). In this work, we bridge the gap between low-pressure and high-pressure experiments and show that there is no controversy.

In most cases, limited amount of works discuss the evolution with pressure of the shape of iron alloys melting diagram. Such diagrams are however required to constrain the partitioning of light elements at the ICB, and the melting temperature depression (relative to the melting point of pure iron) for a given core composition. Also, most of the previous large-volume studies (i.e. multi-anvil studies) used quenched samples that provide information on chemical compositions of solid and liquid eutectic phases and help to bracket the eutectic temperature. Still, quenched experiments are very limited for complete determination of the phase diagram. First, quench experiments do not provide precise information on the position of solidus and liquidus curves in the phase diagram, because of recrystallization during quenching and fast reequilibration owing to the high diffusion rates of light elements in iron (Dobson, 2002). Also, they are not ideal to provide partition coefficients between liquid and solid metallic phases, because of the great difficulty to retrieve sample-areas well representative of the eutectic liquid. Therefore, available constrains on the thermal and chemical state at planetary ICBs must combine both in-situ and chemical analysis on recovered samples.

In this work, we present a new method for determining the melting behaviour of iron alloyed with light elements such as $\mathrm{C}, \mathrm{S}, \mathrm{O}$, and $\mathrm{Si}$. This technique uses the synchrotron 
radiation to measure in situ at high pressure the liquid fraction as a function of temperature, with a high degree of accuracy thanks to the use of the multi-anvil device. Such data allows quantitative determination of the solidus and liquidus lines (Andrault et al., 2006). Also, the quenched samples were analysed using electron microprobe and scanning electron microscope techniques in order to provide constrains on the eutectic composition.

\section{Experimental procedures}

Samples compositions

We studied melting relations for 4 different iron-alloys compositions: $\mathrm{Fe}_{0.9} \mathrm{C}_{0.1}$, $\mathrm{Fe}_{0.78} \mathrm{Ni}_{0.04} \mathrm{Si}_{0.18}, \mathrm{Fe}_{0.87} \mathrm{O}_{0.13}$, and $\mathrm{Fe}_{0.9} \mathrm{~S}_{0.1}$ in atom percents (at\%), which corresponds to $\mathrm{Fe}_{0.977} \mathrm{C}_{0.023}, \mathrm{Fe}_{0.855} \mathrm{Ni}_{0.045} \mathrm{Si}_{0.1}, \mathrm{Fe}_{0.96} \mathrm{O}_{0.04}$, and $\mathrm{Fe}_{0.94} \mathrm{~S}_{0.06}$ in weight percents (wt\%) (see Table 1). All these oxides were prepared from mixing iron metal and oxides except for the $\mathrm{Fe}_{0.78} \mathrm{Ni}_{0.04} \mathrm{Si}_{0.18}$ which was available as an alloy and for which we checked the composition by electron microprobe. For each of these starting materials, except maybe for the $\mathrm{Fe}-\mathrm{O}$ alloy (see the discussion section), the amount of light element should be less than the eutectic composition, and therefore we expected coexistence of light element-depleted solid Fe-alloy and light element-enriched liquid upon partial melting. These samples were intimately mixed with $\mathrm{SiO}_{2}$ powder before being loaded in the sample capsule. After the loading at high pressure and temperature, the $\mathrm{SiO}_{2}$ material produces a connected matrix that prevents liquid iron to coalesce into a large droplet that can move relative to the X-ray beam during the in situ measurement. Thus, all our Fe-alloys equilibrated chemically with $\mathrm{SiO}_{2}$, through a potential dissolution of some $\mathrm{Si}$ and $\mathrm{O}$. We did not observed any $\mathrm{FeSiO}_{3}$ or $\mathrm{Fe}_{2} \mathrm{SiO}_{4}$ phases, which would be expected for very oxidized experimental charges. We note that the choice of $\mathrm{SiO}_{2}$ between other possible capsule material is geophysically relevant, because the iron core has segregated through a silicate matrix (Rubie et al., 2003; Stevenson, 1990). We also analysed the melting temperature of pure Fe embedded into $\left(\mathrm{Mg}_{0.83}, \mathrm{Fe}_{0.17}\right)_{2} \mathrm{SiO}_{4}$ San-Carlos olivine.

A dominant parameter is the oxygen fugacity encountered by our samples. It can play an important role on the melting properties because $\mathrm{O}$ solubility in liquid iron is not negligible. Concerning $\mathrm{Fe}-\mathrm{Si}$ and $\mathrm{Fe}-\mathrm{C}$ alloys, we expect more reducing conditions due to the composition of the alloy itself (Gessmann et al., 1999), as confirmed by the chemical analysis of the recovered samples (see results section). For the Fe-S system, it is known that $\mathrm{S}$ and $\mathrm{O}$ can be compatible in liquid iron up to the immiscibility point (Tsuno et al., 2007). In order to provide more reducing conditions than for $\mathrm{Fe}_{0.9} \mathrm{~S}_{0.1}$ alloy, we prepared another starting material with addition of 2 at $\% \mathrm{Si}$ as FeSi material. For this composition, we also used layers 
of Si-metal located at both capsule ends, in order to prevent any possible O-contamination from the assembly to the sample. More details about sample compositions are provided in

\section{Table 1.}

\section{Sample assembly}

Pressures from 9 to 24 GPa were provided by the SPEED-1500 double stage multi-anvil press installed at BL04B1 beamline of the SPring8 synchrotron (Japan) (Utsumi et al., 2002). We used tungsten carbide anvils with $3 \mathrm{~mm}$ truncations, sitting in the so-called [100] configuration with cube-edges parallel to the compression axis. A new octahedral cell assembly was designed to satisfy the main geometrical constrains for the in situ observations (Fig. 1). The sample and $\mathrm{MgO}$ pressure marker were loaded in a sintered alumina tube of 1 $\mathrm{mm}$ diameter inserted in a $7 \mathrm{~mm} \mathrm{Cr}$-doped $\mathrm{MgO}$ octahedral pressure medium. Sample and a mixture of $\mathrm{MgO}-\mathrm{BN}$ used as a pressure marker are separated by a thin $\mathrm{Al}_{2} \mathrm{O}_{3}$ layer. After the loading was completed, the $\mathrm{Al}_{2} \mathrm{O}_{3}$ tube placed parallel to the opening gap between the WC anvils. The whole sample assemblage was made available to the $\mathrm{X}$-ray probe by lateral scanning of the press.

Temperatures up to $1700^{\circ} \mathrm{C}$ were provided by resistance heating of two $\mathrm{LaCrO}_{3}$ sheet furnaces located above and below the $\mathrm{Al}_{2} \mathrm{O}_{3}$ tube of $0.2 \mathrm{~mm}$ thickness. Temperature was monitored using a $\mathrm{WRe}_{3} / \mathrm{WRe}_{25}$ thermocouple running parallel to the $\mathrm{Al}_{2} \mathrm{O}_{3}$ sample container. Both sample and junction are located at equal distances from the two sheet furnaces. In this configuration, temperature reproducibility is estimated to be better than 30 degrees. Some errors may arise from the variation of the thermocouple properties under pressure. The systematic error is probably less than $+/-30 \mathrm{~K}$, as suggested by recent study of the effect of pressure on the relation between emf and temperature ( $\mathrm{Li}$ et al., 2003). We preferred to neglect this correction, because the knowledge of its amplitude remains limited. In addition, most of works use uncorrected temperatures.

\section{In situ X-ray diffraction}

We performed both in situ x-ray imaging and x-ray diffraction. The 2-dimensional imaging of x-ray absorption contrast was used to check the quality of the sample assemblage after compression to the target pressure, and also to localize the sample and $\mathrm{MgO}$ pressure marker. $\mathrm{X}$-ray diffraction measurements were performed in the energy dispersive mode, for 2-theta diffraction angles around 6 degrees, and diffraction peaks could be observed in the 30 to 130 $\mathrm{keV}$ energy range. The $\mathrm{X}$-ray spot size was $50 \times 100 \mu \mathrm{m}$. Typical acquisition time was 300 
sec. All diffraction patterns were treated using the GSAS-code which allows multi-phase analysis from direct fitting of the diffraction pattern (Larson and Von Dreele, 1988). Diffraction patterns of the mixture of $\mathrm{MgO}$ and $\mathrm{BN}$ were regularly recorded during increase or decrease of the temperature, to derive experimental pressure from the PVT equation of state of $\mathrm{MgO}$ (Jamieson et al., 1982). The MgO-BN marker is sitting at less than 300 microns away from the sample (see Fig. 1 in (Andrault et al., 2006)). Therefore, after the stresses are correctly released at about $1000 \mathrm{~K}$ by checking peak width, the uncertainty in pressure measurements relies only on the quality of the temperature measurement (better than $50 \mathrm{~K}$ ), and on the knowledge of the PVT equation of state (EoS) of $\mathrm{MgO}$. The sample pressure was also checked using the PVT EoS of stishovite (mixed with the sample) (Liu et al., 1999; Nishihara et al., 2005). The results provided by the two EoS are similar within the experimental uncertainties. According to the resolution of the X-ray diffraction experiment and to the temperature uncertainty, we estimate that the sample pressure is known to accuracy better than 0.5 GPa. Other experimental details are reported elsewhere (Andrault et al., 2006).

\section{Temperature uncertainty}

In this work, we use two types of sensors to estimate the temperature uncertainty. The first is the well-known phase diagram of iron. For example, we observed coexistence of $\alpha, \beta$ and $\gamma$ forms of iron at $9 \mathrm{GPa}$ and $728 \mathrm{~K}$, which is in very good agreement with the previously reported position for the iron triple point (Fig. 2). We also report the P-T conditions at which we observed the onset of the phase transformation from the $\varepsilon$ to the $\gamma$ form of pure iron upon heating at high pressure. This transition could be easily identified because most of our starting materials contain some pure $\mathrm{Fe}$ and temperatures are low enough to prevent any reaction. The transition temperatures are found in quite good agreement with the phase boundary determined previously (Boehler, 1986; Funamori et al., 1996). These observations guarantee the internal consistency of our temperature reading and evidence no systematic error in our temperature measurements. Two data points, however, seem to plot at too low temperature compared to those expected for the $\varepsilon$ to $\gamma$ Clapeyron slope. Therefore, for the experiments labelled "6" and "11" (Fig. 2), we re-evaluate all temperatures by addition of $100 \mathrm{~K}$ to the thermocouple readings.

The second sensor used to check the reliability in temperature readings is provided by iron melting in experiments 1-3, where samples correspond to pure $\mathrm{Fe}$ embedded into $\left(\mathrm{Mg}_{0.83}, \mathrm{Fe}_{0.17}\right)_{2} \mathrm{SiO}_{4}$ San-Carlos olivine. In a previous experimental work performed at 16 
GPa, Ringwood and Hibberson (Ringwood and Hibberson, 1991) evidenced a melting temperature depression relative to that of pure $\mathrm{Fe}, \Delta \mathrm{T}_{\mathrm{m}}$, of $70 \mathrm{~K}$ and $275 \mathrm{~K}$ for the melting of iron in $\mathrm{Fe}_{-} \mathrm{SiO}_{2}$ and $\mathrm{Fe}-\mathrm{FeO}$ systems, respectively. Our investigation of iron-melting using the samples made of a mixture of iron and olivine are perfectly compatible with this trend. We observed melting-temperature depression $\left(\Delta \mathrm{T}_{\mathrm{m}}\right)$ of $\sim 250 \mathrm{~K}$, between 16 to $24 \mathrm{GPa}$, compared to the melting curve of pure iron (Boehler, 1986; Shen et al., 1993). This temperature depression is due to reaction between $\mathrm{Fe}$ and olivine.

\section{Microanalyses of recovered samples}

Chemical composition and microstructure of the recovered samples were measured using electron probe microanalysis (EPMA) and scanning electron microscope (EDS-SEM). Because some parts of our Fe-alloys appear zoned at a few micron scale, we reduced the tension of the EPMA electron gun to 10 or $15 \mathrm{keV}$ and the electron beam intensity to $4 \mathrm{nA}$ in order to minimize the analysed zone. 2D modelling of the experimental conditions suggests that the signal comes from a sample zone of less than $0.2 \mu \mathrm{m}$ depth and $0.3 \mu \mathrm{m}$ diameter. As calibrant, we used $\mathrm{Fe}_{2} \mathrm{O}_{3}$ for $\mathrm{O}$ and $\mathrm{Fe}$, diopside for $\mathrm{Si}, \mathrm{FeS}_{2}$ for $\mathrm{S}$, and $\mathrm{NiO}$ for $\mathrm{Ni}$.

\section{Results}

Melting of iron-alloys

X-ray diffraction patterns were first collected during temperature increase. Different criteria were used to detect the onset of sample melting. Very rapid changes of the intensity of Bragg peaks of iron first demonstrate fast grain rotation at the onset of melting. Also, we observed a drastic change in shape of the background of diffraction profiles. A broad band contribution appears due to the diffuse $\mathrm{x}$-ray scattering of liquid iron. This band can be easily distinguished from the Compton diffusion of the cell assembly, because it is located in a much more limited energy range (Fig. 3). This observation is perfectly compatible with previous works performed on metallic liquids (e.g. (Sanloup et al., 2000; Tsuji et al., 1989)). The signal of diffuse scattering can be filtered out of the diffraction patterns by removal of the diffraction peaks of the pressure medium (using peak fitting), and after subtraction of the background due to Compton-diffusion in the octahedral assemblage. More details and complementary experiments about this matter are reported elsewhere (Andrault et al., 2006). Backgrounds recorded before and after investigating the iron melting are similar within the experimental uncertainty, pointing out to the lack of significant drift of the background shape, hence no element loss, during the time of the experiments. Therefore, we considered the iron-alloy fully 
molten when the intensity of the band of diffuse x-ray scattering remained maximum and unchanged on further temperature increase. The lowest temperature at which iron is fully molten corresponds to the liquidus temperature for a given sample composition in the binary phase diagram between iron and the light element (as reported in Table 1).

\section{Band of diffuse scattering}

Due to a relatively limited reciprocal space available from our diffraction signal, we do not claim for a structural refinement as performed in previous works (see (Tsuji et al., 1989), for example). Still, the energy position of the diffuse x-ray scattering band is directly correlated with the local structure of the liquid iron-alloy. We investigated the inter-atomic bonding using the simplest technique based on the assumption that the local structure in the liquid should be similar to that found in nano-crystals. The decrease of grain size from the micron scale to the nanometer scale (and further on to the liquid-state) affects the shape of the diffraction line by significant broadening. This approach has been shown to be useful to derive the local structure in liquids and glasses (Le Bail, 1995). In order to reproduce the diffuse $\mathrm{x}$-ray scattering patterns recorded at high pressure and temperature, we tested bcc, fcc, and hcp structures, those being the three different models possible for iron at conditions the present experiments. For example, we report experimental data for the Fe-C system at 20.7 GPa and $1573 \mathrm{~K}$ (Exp. 846; Table 1) together with the calculations using the different structural models for the liquid (Fig. 4). The best fit is obtained for a bcc-derived structure with $11.84 \AA^{3}$ per iron atom, which corresponds to a mean first Fe-Fe bond length of $2.49 \AA$ with possibly 8 iron neighbours. With the same structural model, we obtain $\mathrm{Fe}-\mathrm{Fe}$ bond lengths of $2.43 \AA$ and $2.47 \AA$ for Fe-S system at $20.7 \mathrm{GPa}$ and FeNi-Si system at $16.0 \mathrm{GPa}$, respectively. All values appear comparable to each other considering to the precision of our technique. Our results are in agreement with a recent work that proposed a bcc-like structure for liquid iron at low pressure and temperature (Sanloup et al., 2000), but disagree with this same work about the fact that pressures above $\sim 4 \mathrm{GPa}$ would favour the fcc-like liquidstructure. Note, however, that the previous work was performed on pure iron at much higher temperatures than ours.

For the Fe-S sample (S848), we notice a peculiar structural behaviour of the liquid Fealloy. Indeed, while the main band of diffuse x-ray scattering, located at $\sim 55 \mathrm{keV}(\sim 1.97 \AA)$, is observed to decrease in intensity with decreasing temperature (Fig. 5d), we also observe a second band of diffuse scattering located at $\sim 66 \mathrm{keV}(\sim 1.65 \AA)$. Its relative intensity increases with decreasing amount of liquid in the sample. While the main band at $55 \mathrm{keV}$ is well 
explained by Fe-Fe atomic pair contribution, the energy position of the second band at $66 \mathrm{keV}$ is well explained by presence of Fe-S pairs at $\sim 2.0 \AA$ in the metallic liquid. This is well explained by the fact that at low liquid fraction, the liquid is largely enriched in S, thus displaying a high intensity for the Fe-S contribution. This behaviour is logical given the incompatibility of S with solid-Fe in this pressure range (Li et al., 2001). Similar behaviour is suggested by the same type of doublet (see Fig. 5c) for the Fe-O sample (S1432,).

\section{Partial crystallization}

After complete melting, and therefore homogenisation, of the alloy, we collected x-ray diffraction patterns as a function of decreasing temperature. During slow cooling, and thus progressive re-crystallization of the iron-alloy, the iron peaks remain scarce due to a reduced number of crystallites. Therefore, the intensity of diffraction lines is not reproducible with the sample orientation, which disables the use of peak intensity to retrieve the solid-Fe content. Still, we observe that the first iron structure to appear is $\gamma$-fcc for all compositions investigated in this study. Important information arises from the intensity of the band of diffusion x-ray scattering, which is observed to decrease with decreasing temperature for all samples investigated (Fig. 5). This behaviour is due to a change of the melt fraction as a function of temperature, as the experimental path is crossing a two-phase loop in the phase diagrams (Table 1). Note that the coexistence of solid and liquid phases cannot be explained by temperature gradients because of the very small $\mathrm{x}$-rayed volume of about $\sim 210^{-3} \mathrm{~mm}^{3}$ (see (Andrault et al., 2006)). Also, the high thermal conductivity of the sample is likely enhancing temperature homogenisation. The intensity of the diffuse x-ray scattering is directly proportional to the liquid mass, because the sample is stationary relative to the $\mathrm{x}$-ray beam during the whole cycle (thanks to the presence of the $\mathrm{SiO}_{2}$-matrix). Thus, the intensity of the diffuse-scattering signal can be used to retrieve the degree of sample melting as a function of temperature (see (Andrault et al., 2006) for more details). In order to scale intensity, we normalized it to the maximum intensity as recorded for the fully molten sample.

\section{Comparative behaviour of $\mathrm{Fe}$-alloys}

In general, we observe an increase of eutectic temperature with increasing pressure of 50 degrees $\mathrm{K}$ from 16.9 to $22 \mathrm{GPa}$ in the $\mathrm{Fe}-\mathrm{Ni}-\mathrm{Si}\left(9.8^{\circ} \mathrm{K} / \mathrm{GPa}\right)$, of 50 degrees from 16.5 to 20.5 $\mathrm{GPa}$ in the Fe-O system $\left(12.5^{\circ} \mathrm{K} / \mathrm{GPa}\right)$, and of 100 degrees $\mathrm{K}$ from 15 to $20.6 \mathrm{GPa}$ in the Fe-S system $\left(17.9^{\circ} \mathrm{K} / \mathrm{GPa}\right)$, see Table 1 . The addition of Si metal as an oxygen trap apparently has little effect on the eutectic temperature. For Fe-C, FeNi-Si, and Fe-O samples, the coexistence 
of solid and liquid phases occurs on a reduced temperature range of around $100 \mathrm{~K}$. The behaviour of the Fe-S sample is significantly different, as the band of diffuse x-ray scattering remains clear over an extended interval of $\sim 350 \mathrm{~K}$ temperature (Figs. 5 and 6). This behaviour depends on the nature of the light element and shape of eutectic melting diagrams. A reduced temperature range for coexistence of solid and liquid can result from two different situations: either there is an extended solubility of the light element in solid $\mathrm{Fe}$ and therefore the melting loop is relatively narrow, or the sample composition is close to that of the eutectic liquid. Whereas, an extended temperature range points out to a broad melting loop and a sample composition significantly away from that of the eutectic liquid.

It is important to note that our procedure to determine eutectic temperature (and also eutectic composition, see below) is largely different from previous works. Previous melting determinations were based on quenched textures or rarely on changes of electrical resistivity, for samples that have been once heated to a given target temperature. In our work, the sample has first undergone melting to temperatures significantly above the eutectic temperature, before the temperature is reduced. During cooling, crystallisation occurs and the liquid gets naturally enriched in light elements. Using this procedure, (a) there is no problem with kinetic problems associated to diffusion of light elements into the solid phases and (b) the final liquid gathers all elements that are incompatible with solid iron (and the surrounding stishovite). One could argue that there are other impurities, not relevant to our Fe-alloy systems, that would artificially lower the eutectic temperature. According to our experimental charge, the impurities are likely to be extra $\mathrm{O}$ and/or $\mathrm{Si}$ coming from the $\mathrm{SiO}_{2}$ matrix. This is possible, but as stated in "experimental procedure" section, the choice of $\mathrm{SiO}_{2}$ is more geophysically relevant than for other possible capsule material.

\section{Microanalyses of recovered samples}

Electron microprobe and SEM observations evidence that the metallic grains are chemically zoned (Fig. 7). Concerning the $\mathrm{Fe}_{0.9} \mathrm{C}_{0.1}$ sample, back scattering electron images display brighter and darker alternating stripes at a few microns scale (Fig. 7a). The $\mathrm{C}$ content could not be measured in this study, however, the EPMA analyses show significantly different weight totals of 94.7(1) or 92.2(2) wt\% for brighter and darker zones, respectively (Table 2). This suggests differences in $\mathrm{C}$ contents in these two types of material. Also a similar compositional contrast is obtained after point-beam analysis in the SEM as evidenced by the two darker spots in this figure, because this type of analysis deposits carbon on the sample. This observation indicates that the contrast is due to carbon. Actually, this type of stripe-like 
zonations is similar to those found in pearlites. The brighter zone is depleted in carbon and therefore represents the composition of the solid at the complete solidification temperature whereas the darker zone is enriched in the light element. The $\mathrm{O}$ content in the different parts of the sample is negligible, which indicates incompatibility between $\mathrm{C}$ and $\mathrm{O}$ in liquid $\mathrm{Fe}$. Also, very moderate Si-contents of about $0.1 \mathrm{wt} \%$ show very limited reactions between liquid $\mathrm{Fe}-\mathrm{C}$ alloy and $\mathrm{SiO}_{2}$.

For the $\mathrm{Fe}_{78} \mathrm{Ni}_{4} \mathrm{Si}_{18}$ composition, the two available samples appear homogeneous in microstructure and composition, except in some regions where we observe significant contrast on electronic images (Fig. 7b). The EPMA analyses of the darker and homogeneous area yield 8.6(2) and 8.9(3) wt\% Si for the 16.9 and $22 \mathrm{GPa}$ sample, respectively (Table 2). These Si-contents are just below the $10 \mathrm{wt} \% \mathrm{Si}$ present in the starting material. The brighter region shows a composition enriched in Si with 9.1 or $13.1 \mathrm{wt} \% \mathrm{Si}$ for samples at 16.9 and $22 \mathrm{GPa}$, respectively. The reason why this region appears brighter in the SEM, even if it has a (slightly) higher mean $\mathrm{Si}$ content, is due to a significantly higher Ni content. In the $16.9 \mathrm{GPa}$ sample, we found locally some values compatible with the (Fe,Ni) $)_{3} \mathrm{Si}$ stoichiometry. This zone is typical of quenched eutectic liquids, when two solid phases are produced simultaneously on crystallization. Thus, due to the exsolution of the liquid at the eutectic temperature it is difficult to determine accurately the eutectic composition on the basis of the EPMA analysis only. The presence of a large majority of dark, Si-poor phase and minor amounts of the bright, Si-rich phase is indicative that the eutectic composition is only slightly enriched in Si compared to the solid. Note that such high Si-contents can only be obtained for a low oxygen fugacity (Gessmann et al., 2001), as confirmed by the negligible O content measured in this sample. For the sample at $22 \mathrm{GPa}$, the microstructure appears similar. However, we note a relatively higher Si-partitioning into the eutectic liquid correlated with a Ni-partitioning close to unity (Table 2). For the $\mathrm{Fe}_{0.9} \mathrm{O}_{0.1}$ composition, the SEM images of the two samples available show a minor darker phase always at the edges of a very bright and dominant phase (Fig. 7c: The black phase in this figure is the $\mathrm{SiO}_{2}$ matrix). This microtexture suggests that these two phases were immiscible at high temperature. The EPMA analyses point out that these dark and bright phases are almost pure $\mathrm{FeO}$ and $\mathrm{Fe}$, respectively (Table 2). The $\mathrm{O}$ content in the Fe-phase is below the detection limit, and no blob-like texture typical of oxygen exsolution was observed. The Si content is found slightly above the detection limit in the Fe-phase. 
For $\mathrm{Fe}_{0.9} \mathrm{~S}_{0.1}$ samples with or without $\mathrm{Si}$ additions, two sample regions are visible (Fig. 7d). A first one appears brighter and homogeneous with $S$ contents limited to about $0.1 \mathrm{wt} \%$ (Table 2). This measurement was reproduced with varying electron beam conditions. We also performed energy scans in order to check an eventual shift of the S-peak. This value is significantly lower than the $0.4 \mathrm{wt} \%$ reported at $20 \mathrm{GPa}$ ( $\mathrm{Li}$ et al., 2001). A possible explanation can be related to differences in the quenching procedure. In our case, we performed very slow cooling rates in order to acquire X-ray diffraction patterns of the melting loop phases. Thus, the whole crystallization process extended over more than 1 to 2 hours. This has potentially facilitated atomic diffusion and achievement of thermodynamical equilibrium, whereas other multi-anvil studies rapidly quenched the samples and the size of the eutectic phases are smaller. Another possible explanation for the low S solubility of the iron solid in this study is the presence of $\mathrm{Si}$ in our assemblages in order to buffer the oxygen fugacity to low values. A second part shows two phases with a microstructure typical of exsolution during quenching of eutectic liquids. The most S-rich phase shows $\sim 23.5 \mathrm{wt} \% \mathrm{~S}$, at 18.5 $\mathrm{GPa}$, which composition is close to the stoichiometry of the $\mathrm{Fe}_{2} \mathrm{~S}$ compound. The occurrence of $\mathrm{Fe}_{2} \mathrm{~S}$ phase has already been reported (Siebert et al., 2004). Due to the high heterogeneity, we found it difficult to determine a mean $\mathrm{S}$ content for the eutectic liquid. The value of $\mathrm{S}$ in the enriched phase reported in Table 2 therefore probably overestimates the $\mathrm{S}$ content of the eutectic liquid. The $\mathrm{O}$ content of the alloys appears significantly lower for the two samples where Si was added, which indicates lower oxygen fugacities.

\section{Discussion}

\section{Drawing melting diagrams at high pressure}

Using all information retrieved from the in situ measurements and EPMA analyses on samples quenched from eutectic temperatures, we expect to draw binary phase diagrams and melting loops at high pressure. Our procedure is as follows: (1) the solidus and liquidus temperatures are provided by the in situ measurements of the liquid content as a function of temperature (Fig. 6). Whether the complete solidification temperature represents the solidus or the eutectic depends on the bulk composition relative to the maximum solubility of the light element in solid iron. If the bulk light element concentration is lower than the maximum solubility of this element in solid iron then the whole sample solidifies at temperatures above the eutectic temperature. (2) In this study, most quenched samples consisted of at least two phases (see Fig. 7), thus solidification temperatures represent the eutectic temperatures. (3) EPMA analysis provides composition of solid and liquid phases at the eutectic temperature 
(Table 2). As mentioned in the introduction, it can be difficult to estimate the liquid composition precisely in some cases, because crystallization of the eutectic liquid yields two different solid phases which size depends on the atomic diffusion rates. (4) The solidus curve is considered to be a straight line between melting temperature of pure $\mathrm{Fe}$ at the experimental pressure and eutectic solid. (5) Relative amounts of solid and liquid phases in extended temperature ranges are provided by the intensity of the iron diffusion band measured in situ (Figure 6). For a given starting composition, this information allows to constrain the position of the liquidus curve compared to that of the solidus using the simple law of mass conservation. (6) Each temperature step provides an independent position of the liquidus curve. The extrapolation of this curve down to the eutectic temperature provides independent information of the composition of the eutectic liquid.

For this procedure, melt fractions below $30 \%$ are not considered because their determination is affected by significantly higher experimental errors. Another important source of error is related to the determination of the eutectic temperature from our data set. This error is roughly similar to the temperature increment $\Delta \mathrm{T}$ used for our crystallization experiments, often set to $50 \mathrm{~K}$ (Fig. 6). This $\Delta \mathrm{T}$ errors transfer to errors in light element contents from 0.2 to $1 \mathrm{wt} \%$, depending on the shape of the phase diagrams (Fig. 8).

\section{The Fe-C system}

At ambient pressure, the $\mathrm{Fe}-\mathrm{C}$ binary diagram contains an eutectic point at $1403 \mathrm{~K}$ and 4.3 $\mathrm{wt} \% \mathrm{C}$. At this temperature, solid iron, austenite, dissolves $1.7 \mathrm{wt} \%$ carbon. It has been proposed that the eutectic temperature increases with pressure linearly with a slope of $\sim 7$ $\mathrm{K} / \mathrm{GPa}$ (Hirayama et al., 1993). The eutectic temperature of $1460 \mathrm{~K}$ observed in this study at 20.7 GPa falls slightly below a linear extrapolation of their data but still agrees with this trend within the error of both studies. It is possible that the solidification temperature observed in this sample is not the eutectic temperature but the solidus because the starting material composition at about $2.3 \mathrm{wt} \% \mathrm{C}$ is close to the saturation value for solid iron at $1 \mathrm{bar}$. However, according to the thermodynamic calculations by Wood (Wood, 1993), the eutectic $\mathrm{C}$ content and $\mathrm{C}$ solubility in solid iron decrease with increasing pressure until at $15 \mathrm{GPa}$, the model yields less than $1 \mathrm{wt} \% \mathrm{C}$ in solid iron at eutectic temperature. Still, the results of Hirayama et al., 1993 and Wood, 1993 are being challenged by recent experimental data (Fei et al., 2007).

\section{The FeNi-Si system}


The eutectic point in the Fe-Si binary join is located at $1463 \mathrm{~K}$ at atmospheric pressure, with $18.5 \mathrm{wt} \% \mathrm{Si}$. For the $\mathrm{Fe}_{78} \mathrm{Ni}_{4} \mathrm{Si}_{18}$ compound, we observed complete crystallization of the iron alloy at 1423 and $1473 \mathrm{~K}$ for 16.9 and $22 \mathrm{GPa}$, respectively, indicating that eutectic temperatures have very small pressure dependence in the Fe-Ni-Si system (Table 1). According to the eutectoid microstructure of the recovered samples described above (Fig. 7b), it is very likely that these temperatures correspond to eutectic temperatures in the FeNi-Si diagrams. These are significantly lower than previously reported in the Fe-Si system. In a first work, the melting temperature of $\mathrm{Fe}_{83} \mathrm{Si}_{17}$ was found to increase from 1473 to $\sim 1693 \mathrm{~K}$ with increasing pressure to $5.5 \mathrm{GPa}$ (Yang and Secco, 1999). However, the reported experimental procedure was not sensitive to the differences between eutectic, solidus, and liquidus temperatures. In a second work performed at $21 \mathrm{GPa}$, the eutectic temperature are reported at $2093 \mathrm{~K}$ (Kuwayama and Hirose, 2004), at only 100 degrees $\mathrm{K}$ lower than the melting temperature of pure iron expected at $\sim 2200 \mathrm{~K}$ at $21 \mathrm{GPa}$ (Boehler, 1986; Shen et al., 1993). We find that a temperature depletion of only $\sim 100 \mathrm{~K}$ compared to pure iron melting is questionable. (Kuwayama and Hirose, 2004) also reported an eutectic composition at 25.1 $\mathrm{wt} \% \mathrm{Si}$.

At $16.9 \mathrm{GPa}$, chemical analyses of the recovered sample indicate $8.6 \mathrm{wt} \% \mathrm{Si}$ in the homogeneous solid phase at the eutectic temperature of $1423 \mathrm{~K}$ (Table 2). Also, in situ x-ray diffraction patterns indicate $65 \%$ melt at an intermediate temperature of $1473 \mathrm{~K}$ (Fig. 6). The diagram reconstructed from these observations shows a narrow loop diagram, crystallization occurring over a narrow temperature range (Fig. 8a). This narrow loop is in agreement with the large abundance of the Si-poor phase as analysed on the recovered sample (see above). The extrapolation of the liquidus curve to the eutectic points out to an eutectic liquid composition with $11.5(2) \mathrm{wt} \% \mathrm{Si}$ at $16.9 \mathrm{GPa}$. This value is higher than determined by EPMA at $9.1 \mathrm{wt} \%$ in the Si-rich region. This discrepancy can be related to the heterogeneous nature of the quenched eutectic liquid, which disables accurate EPMA measurement. Such difference determines the error bar in the determination of the eutectic composition in Fig. 8a. At 22 GPa the EPMA analysis indicates an eutectoid composition of $13.1 \mathrm{wt} \% \mathrm{Si}$ whereas the Sipoor region contains $8.9 \mathrm{wt} \% \mathrm{Si}$ (Table 2).

Compared to the value of $18.5 \mathrm{wt} \% \mathrm{Si}$ in the eutectic liquid at room pressure, our results show that the Si content in the eutectic liquid has decreased at high pressures. The solubility of $\mathrm{Si}$ in the solid also decreases with increasing pressure but the resulting partition coefficient of Si between coexisting liquid and solid phase $\mathrm{D}^{\mathrm{Si}}$ liq/sol as increased from 1.11 at ambient 
pressure to $1.35(10)$ at $16.9 \mathrm{GPa}$. Thus, the effect of pressure is to increase the width of the melting loop.

\section{The Fe-S system}

At room pressure, the Fe-S system displays an eutectic at $1261 \mathrm{~K}$ and $31.2 \mathrm{wt} \% \mathrm{~S}$, with FeS being the S-rich phase. For a $\mathrm{Fe}_{94} \mathrm{~S}_{6}$ composition we observe significantly lower eutectic temperatures at 15 to $20.6 \mathrm{GPa}$ (Table 1 and Fig. 9). Our results are in agreement with multianvil data (Fei et al., 1997; Fei et al., 2000; Li and Agee, 2001; Stewart et al., 2007) that show different trends for pressure evolution of eutectic temperatures. The change in slope of pressure dependence of the eutectic temperature has been explained by the appearance of new phases in the Fe-S system, $\mathrm{Fe}_{3} \mathrm{~S}_{2}$, at $14 \mathrm{GPa}$ and $\mathrm{Fe}_{3} \mathrm{~S}$ at $21 \mathrm{GPa}$ (Fei et al., 1997; Sherman, 1995). Recent LH-DAC reports of melting in the Fe-S system finally agree with results obtained using large volume presses (Campbell et al., 2007; Chudinovskikh and Boehler, 2007; Morard et al., 2007). The eutectic temperatures determined in this study appear slightly lower than previous large volume press experiments, by $\sim 100 \mathrm{~K}$, due to the fact that our detection method is more sensitive to small degrees of partial melting (see Figure 6).

The melting loop in the Fe-S system at $18.5 \mathrm{GPa}$ is shown in Fig. 8d. (1) A straight line corresponding to the solidus is drawn between melting temperature of pure Fe at $\sim 2200 \mathrm{~K}$ (Boehler, 1986; Shen et al., 1993) and the eutectic solid phase at $1073 \mathrm{~K}$ composed of $\sim 0.1$ wt $\%$ S. (2) For this $\mathrm{Fe}_{94} \mathrm{~S}_{6}$ bulk composition, we found the liquidus temperature at $1523 \mathrm{~K}$. (3) At all temperatures where solid and liquid coexist in varying proportions (Fig. 6), we can constrain the position of the liquidus curve. For example, at $1190 \mathrm{~K}$, we observed $48 \%$ of the sample molten, which implies a liquidus composition of $\sim 10.5 \mathrm{wt} \% \mathrm{~S}$ at this temperature. (4) In a last step, we extrapolate the liquidus curve down to the eutectic temperature. We obtain an eutectic composition of $\sim 14.5(5) \mathrm{wt} \% \mathrm{~S}$ at $18.5 \mathrm{GPa}$ that is comparable with previous results. Indeed, a significant decrease of the $\mathrm{S}$ content of the eutectic has been reported with increasing pressure from $31.2 \mathrm{wt} \% \mathrm{~S}$ at room pressure to $\sim 12 \mathrm{wt} \% \mathrm{~S}$ at $40 \mathrm{GPa}$. Note that the EPMA measurement of the enriched quenched eutectoid phase overestimated the eutectic composition by almost $30 \%$ due to crystallisation of $\mathrm{Fe}_{2} \mathrm{~S}$. Similar procedure performed for experiments in the Fe-S system with FeSi additions yield eutectic liquid compositions at 20(2) and 16.0(5) wt\% S for 15 and 20.6 GPa, respectively (Fig. 8b and 8c).

The high-pressure melting diagram shows coexistence of solid and liquid phases in a large temperature range with a large amount of $\mathrm{S}$ partitioned to the liquid phase during the crystallization on cooling. The shape of this diagram suggests an almost infinite partition 
coefficient of $\mathrm{S}$ between liquid and solid phases at $18.5 \mathrm{GPa}$, especially because of the very low S-solubility in solid Fe that we measured in our samples (see Results section).

\section{The Fe-O system}

At room pressure, the solubility of oxygen in crystalline iron is of $0.21 \% \mathrm{wt} O$ at the eutectic temperature of $1800 \mathrm{~K}$. The eutectic temperature was reported to increase to $1943 \mathrm{~K}$ at 16 $\mathrm{GPa}$, with an eutectic composition becoming more O-rich (between 1.8 and $2.7 \mathrm{wt} \% \mathrm{O}$ ) (Ringwood and Hibberson, 1990). This group also suggested that the melting temperature of Fe decreases by $27.5 \mathrm{~K}$ per solution of $1 \mathrm{wt} \% \mathrm{FeO}(0.23 \mathrm{wt} \% \mathrm{O})$.

From our experiments in the Fe-O system, we observe coexistence of solid and liquid phases between 1623 and $1523 \mathrm{~K}$ on cooling at $20.5 \mathrm{GPa}$, and the presence of almost pure $\mathrm{Fe}$ and $\mathrm{FeO}$ phases in the recovered sample. Comparable results were obtained at $16.5 \mathrm{GPa}$ (Fig. 3 and Table 2). Using our measurements of the melt fraction as a function of temperature, we draw linear extrapolations of the liquidus composition to the eutectic temperature that yield eutectic compositions of 9.0(1.0) and 10.5(1.0) wt\% $\mathrm{O}$ at 16.5 and $20.5 \mathrm{GPa}$, respectively. Because the O-solubility in solid iron is negligible up to at least $20.5 \mathrm{GPa}$, it yields infinite partitioning coefficient of $\mathrm{O}$ at the advantage of liquid iron (Fig. 8e and 8f).

Our results are very different to those of Ringwood's group in the nineties. We have no good explanation for this discrepancy. Concerning the composition of the eutectic liquid, we note that it is particularly difficult to analyze $\mathrm{O}$-content in quench experiments because $\mathrm{FeO}$ blobs exsolve during solidification of the liquid.

\section{Conclusions}

By using in-situ X-ray diffraction we could bracket the melting temperatures of various iron plus light element alloys with high precision in the 15-24 GPa range. The optimal control of temperature and of the degree of melting enables to distinguish between liquidus, solidus and/or eutectic temperature. Interestingly, we observe roughly similar temperature drops, compared to pure iron, for the melting of iron alloys with addition of 10 to 15 at $\%$ of the different (C, Si, O, S) light element (Fig. 2, Table 1). This could be due to the degree of structural transformation of liquid iron induced by the insertion of the light elements, which is to be related with a certain amount of $\mathrm{Fe}-\mathrm{C}, \mathrm{Fe}-\mathrm{Si}, \mathrm{Fe}-\mathrm{O}$ and $\mathrm{Fe}-\mathrm{S}$ atomic bonding. Our results suggest quite significant melting temperature depletion, $\Delta \mathrm{T}_{\mathrm{m}}$, between 600 to $1000 \mathrm{~K}$, due to the presence of light elements. 
Concerning eutectic compositions, we first note that our new experimental procedure using in-situ measurements provides sufficient information to draw complete melting diagrams at high pressure, providing independent determination of the eutectic liquid composition (Fig. 8). For the Fe-S system, our results are in good agreement with previous works. We observe that the eutectic temperature increases from $1023 \mathrm{~K}$ at $15 \mathrm{GPa}$ to $1123 \mathrm{~K}$ at 20.6 GPa and that the eutectic composition decreases with increases pressure, in agreement with previous studies. This good agreement confirms that the measurements performed in this study are correct. Concerning the Fe-C system the eutectic temperature of $1460 \mathrm{~K}$ at $20.7 \mathrm{GPa}$ falls slightly below a linear extrapolation of the data of Hirayama et al. (1993).

Our results disagree considerably with previous studies in the case of the Fe-Ni-Si system and the $\mathrm{Fe}-\mathrm{O}$ system. Indeed we find eutectic temperatures that are much lower than found by (Kuwayama and Hirose, 2004) in the Fe-Ni-Si system or by Ringwood and Hibberson (1990) in the Fe-O system. The eutectic compositions are also very different with values richer in light elements with 8.0 and $10.5 \mathrm{wt} \% \mathrm{O}$ at 16.5 and $20.5 \mathrm{GPa}$ respectively in the case of the Fe-O system compared to the mean value of 2.2 from Ringwood and Hibberson (1990). For the Fe-Ni-Si system the eutectic composition is much poorer in the light element with 13.1 wt $\% \mathrm{Si}$ at $20.5 \mathrm{GPa}$ instead of 25.1 obtained by (Kuwayama and Hirose, 2004). We observe that both the eutectic temperature and composition increase with increasing pressure in the 15-20 GPa range for the Fe-Ni-Si and Fe-O systems.

Our experimental procedure involves slow rates of cooling and very progressive crystallization of the liquid alloy, with characteristic times of a few hours. Therefore, diffusion processes are much facilitated compared to quenched experiments previously performed to study these Fe-alloys eutectic systems. Our sample microstructure is very clear about the equilibrated processes encountered. While we confirm a high solubility of $\mathrm{Si}$ in solid $\mathrm{Fe}$, we find a much lower $\mathrm{S}$ solubility the solid iron at the eutectic temperature compared to previous work. The solubility of $\mathrm{Si}$ and $\mathrm{C}$ with solid iron is likely to remain valid at all pressures. While the S-solubility has been suggested to increase significantly at the Earth's core pressures (Alfè et al., 2002; Boness and Brown, 1990; Sherman, 1995), it does not seem to be significant up to at least $21 \mathrm{GPa}$. For this reason, the partitioning coefficient of $\mathrm{S}$ between liquid and solid iron alloys at $\sim 20 \mathrm{GPa}$ remains very high. This is also the case for $\mathrm{O}$ that was not detected in solid iron in our experimental charges. Therefore, $\mathrm{S}$ and $\mathrm{O}$ could both play a major role in solving the density contrast at inner boundary of planetary cores. 
Acknowledgements : We warmly thank J.L. Devidal, J.M. Hénot, G. Morard, H. Takebe for help and discussions, and Y. Fei, E. Ohtani and H. Terasaki for fruitful comments. This work is an INSU-CNRS and was supported by Diety-INSU and JSPS-CNRS exchange programs.

\section{References:}

Alfè, D., Gillan, M. and Price, G.D., 2003. thermodynamics from first principles: Temperature and composition of the Earth's core. Mineralogical Magazine, 67: 113123.

Alfè, D., Gillan, M.J. and Price, G.D., 2002. Composition and temperature of the Earth's core constrained by combining ab initio and seismic data. Earth and Planetary Science Letters, 195: 91-98.

Allègre, J.A., Poirier, J.P., Humler, E. and Hofmann, A.W., 1995. The chemical composition of the Earth. Earth and Planetary Science Letters, 134: 515-526.

Anderson, W.W. and Ahrens, T.J., 1994. An equation of state for liquid iron and implications for the Earth's core. Journal of Geophysical Research, 99: 4273-4284.

Andrault, D. et al., 2006. Study of partial melting at high pressure using in situ X-ray diffraction. High Pressure Research, 26(3): 267-276.

Birch, F., 1964. Density and composition of mantle and core. Journal of Geophysical Research, 69: 4377-4388.

Boehler, R., 1986. The phase diagram of iron to 430 kbar. Geophysical Research Letters, 13(11): 1153-1156.

Boness, D.A. and Brown, J.M., 1990. The electronic band structures of iron, sulfur, and oxygen at high pressures and the Earth's core. Journal of Geophysical Research, 95(B13): 21721-21730.

Campbell, A.J., Seagle, C.T., Heinz, D.L., Shen, G. and Prakapenka, V.B., 2007. Partial melting in the iron-sulfur system at high pressure: A synchrotron X-ray diffraction study. Physics of the Earth and Planetary Interiors: doi:10.1016/j.pepi.2007.04.001.

Chudinovskikh, L. and Boehler, R., 2007. Eutectic melting in the Fe-S system to $44 \mathrm{GPa}$. Earth and Planetary Science Letters, 257: 97-103.

Dobson, D.P., 2002. Self-diffusion in liquid Fe at high pressure. Physics of the Earth and Planetary Interiors, 130: 271-284.

Fei, Y., Bertka, M.C. and Finger, L.W., 1997. High-pressure iron-sulfur compound, $\mathrm{Fe}_{3} \mathrm{~S}_{2}$, and the melting relations in the Fe-FeS system. Science, 275: 1621-1623.

Fei, Y., Li, J., Bertka, M.C. and Prewitt, C.T., 2000. Structure type and bulk modulus of $\mathrm{Fe}_{3} \mathrm{~S}$, a new iron sulfur compound. American Mineralogist, 85: 1830-1833.

Fei, Y., Wang, Y. and Deng, L., 2007. Melting relations in the Fe-C-S system at high pressure: implications for the chemistry of the cores of terrestrial planets, Lunar and Planetary Science. Lunar and Planetary Institute, Houston, pp. 1231.

Funamori, N., Yagi, T. and Utchida, T., 1996. High pressure and high temperature in situ Xray diffraction study of iron to above $30 \mathrm{GPa}$ using MA8-type apparatus. Geophysical Research Letters, 23: 953-956.

Gessmann, C.K., Rubie, D.C. and McCammon, C.A., 1999. Oxygen fugacity dependence of $\mathrm{Ni}, \mathrm{Co}, \mathrm{Mn}, \mathrm{Cr}, \mathrm{V}$ and $\mathrm{Si}$ partitioning between liquid metal and magnesiowüstite at 9$18 \mathrm{GPa}$ and $2200^{\circ} \mathrm{C}$. Geochimica et Cosmochimica Acta, 63: 1853-1863.

Gessmann, C.K., Wood, B.J., Rubie, D.C. and Kilburn, M.R., 2001. Solubility of silicon in liquid metal at high pressure: implications for the composition of the Earth's core. Earth and Planetary Science Letters, 184: 367-376. 
Hillgren, V.J., Gessmann, C.K. and Li, J., 2000. An experimental perspective on the light element in the Earth's core. In: R.M. Canup and K. Righter (Editors), Origin of the Earth and Moon. University of Arizona Press, Tucson, pp. 245-263.

Hirayama, Y., Fujii, T. and Kurita, K., 1993. The melting relation of the system iron and carbon at high pressure and its bearing on the early stage of the Earth. Geophysical Research Letters, 20: 2095-2098.

Jamieson, J.C., Fritz, J.N. and Manghnani, M.H., 1982. Pressure measurement at high temperature in X-ray diffraction studies: gold as a primary standard. In: S. Akimoto and M.H. Manghnani (Editors), High Pressure Research in Geophysics. Riedel, Boston, pp. 27-48.

Javoy, M., 1995. The integral enstatite chondrite model for the Earth. Earth and Planetary Science Letters, 22: 2219-2222.

Kilburn, M.R. and Wood, B.J., 1997. Metal-silicate partitioning and the incompatibility of S and Si during core formation. Earth and Planetary Science Letters, 152: 139-148.

Kuwayama, Y. and Hirose, K., 2004. Phase relations in the system Fe-FeSi at $21 \mathrm{GPa}$. American Mineralogist, 89: 273-276.

Larson, A.C. and Von Dreele, R.B., 1988. GSAS Manual, Los Alamos National Laboratory.

Le Bail, A., 1995. Modeling the silica glass structure by the Rietveld method. Journal of NonCrystalline Solids, 183: 39-42.

Li, B., Hadidiacos, C., Mao, H.K., Fei, Y. and Hemley, R.J., 2003. Behavior of thermocouples under high pressure in a multi-anvil apparatus. High Pressure Research, 23(4): 389-4.1.

$\mathrm{Li}, \mathrm{J}$. and Agee, C.B., 2001. The effect of pressure, temperature, oxygen fugacity and composition on partitioning of nickel and cobalt between liquid Fe-Ni-S alloy and liquid silicate: Implications for the Earth's core formation. Geochimica et Cosmochimica Acta, 65: 1821-1832.

Li, J., Fei, Y., Mao, H.K., Hirose, K. and Shieh, S.R., 2001. Sulfur in the Earth's inner core. Earth and Planetary Science Letters, 193: 509-514.

Liu, J. et al., 1999. Thermal equation of state of stishovite. Physics of the Earth and Planetary Interiors, 112(3-4): 257-266.

Majewski, E. and Walker, D., 1998. S diffusivity in Fe-Ni-S-P melts. Earth and Planetary Science Letters, 160: 823-830.

Malavergne, V. et al., 2004. Si in the core? New high-pressure and high-temperature experimental data. Geochimica et Cosmochimica Acta, 68: 4201-4211.

Mao, H.K., Wu, Y., Chen, L.C., Shu, J.F. and Jephcoat, A.P., 1990. Static compression of iron to $300 \mathrm{GPa}$ and $\mathrm{Fe}_{0.8} \mathrm{Ni}_{0.2}$ alloy to $260 \mathrm{GPa}$ : Implications for composition of the core. Journal of Geophysical Research, 95: 21737-21742.

McDonough, W.F. and Sun, S.S., 1995. The composition of the Earth. Chemical Geology, 120: $223-253$.

Morard, G. et al., 2007. In situ determination of Fe-FeS phase diagram to $65 \mathrm{GPa}$ : implication for the S-content in the Earth's core. Earth and Planetary Science Letters, 272: 620626.

Nishihara, Y., Nakayama, K., Takahashi, E., Iguchi, T. and Funakoshi, K., 2005. P-V-T equation of state of stishovite to the mantle transition zone conditions. Physics and Chemistry of Minerals: in press.

Ohtani, E., Ringwood, A.E. and Hibberson, W., 1984. Composition of the core, II. Effect of pressure on solubility of $\mathrm{FeO}$ in molten iron. Earth and Planetary Science Letters, 71: 94-103. 
O'Neill, H.S.C., Canil, D. and Rubie, D.C., 1998. Oxide-metal equilibria to $2500^{\circ} \mathrm{C}$ and 25 GPa: Implications for core formation and the light component in the Earth's core. Journal of Geophysical Research, 103: 12239-12260.

Poirier, J.P., 1994. Light elements in the Earth's outer core: A critical review. Physics of the Earth and Planetary Interiors, 85: 319-337.

Ringwood, A.E. and Hibberson, W., 1990. The system Fe-FeO revisited. Physics and Chemistry of Minerals, 17: 313-319.

Ringwood, A.E. and Hibberson, W., 1991. Solubilities of mantle oxides in molten iron at high pressures and temperatures: impliocations for the composition and formation of the Earth's core. Earth and Planetary Science Letters, 102: 235-251.

Rubie, D.C., Melosh, H.J., Reid, J.E., Liebske, C. and Righter, K., 2003. Mechanism of metal-silicate equilibration in the terrestrial magma ocean. Earth and Planetary Science Letters, 205: 239-255.

Sakai, T. et al., 2006. Interaction between iron and post-perovskite at core-mantle boundary and core signature in plume source region. Geophysical Research Letters, 33: L15317, doi:10.1029/2006GL026868.

Sanloup, C., Guyot, F., Gillet, P. and Fei, Y., 2002. Physical properties of liquid Fe alloys at high pressure and their bearings on the nature of metallic planetary cores. Journal of Geophysical Research, 107(B11): 2272.

Sanloup, C. et al., 2000. Structural changes in liquid Fe at high pressures and high temperatures from synchrotron X-ray diffraction. Europhysics Letters, 52: 151-157.

Shen, G., Lazor, P. and Saxena, S.K., 1993. Melting of wüstite and iron up to pressures of 600 kbar. Physics and Chemistry of Minerals, 20: 91-96.

Sherman, D.M., 1995. Stability of possible Fe-FeS and Fe-FeO alloy phases at high pressure and the composition of the Earth's core. Earth and Planetary Science Letters, 132: 8798.

Siebert, J., V., M., Guyot, F., Combes, R. and Martinez, I., 2004. The behaviour of sulphur in metal-silicates core segregation experiments under reducing conditions. Physics of the Earth and Planetary Interiors, 143-144: 433-443.

Stevenson, D.J., 1990. Fluid dynamics of core formation. In: H. Newsom and J.H. Jones (Editors), The origin of the Earth. Oxford Press, London, pp. 231-249.

Stewart, A.J., Schmidt, M.W., van Westrenen, W. and Liebske, C., 2007. Mars: A new corecrystallization regime. Science(316): 1323-1327.

Stewart, A.J., Schmidt, M.W., van Westrenen, W. and Liebske, C., 2008. Mars: A new corecrystallization regime. Science(316): 1323-1327.

Takafuji, N., Hirose, K., Mitome, M. and Bando, Y., 2005. Solubilities of O and Si in liquid iron in equilibrium with $(\mathrm{Mg}, \mathrm{Fe}) \mathrm{SiO}_{3}$ perovskite and the light elements in the core. Geophysical Research Letters, 32: L06313.

Tsuji, K., Yaoita, K., Imai, M., Shimomura, O. and Kikegawa, T., 1989. Measurements of xray diffraction for liquid metals under high pressure. Review of Scientific Instruments, 60(7): 2425-2428

Tsuno, K., Ohtani, E. and Terasaki, H., 2007. Immiscible two liquid regions in the Fe-O-S system at high pressure: Implications for planetary cors. Physics of the Earth and Planetary Interiors, 160: 75-85.

Urakawa, S., Kato, M. and Kumazawa, M., 1987. Experimental study on the phase relations in the system Fe-Ni-O-S. In: M.H. Manghnani and Y. Syono (Editors), High-Pressure Research in Mineral Physics. Tokyo, TERRAPUB, Washington, D.C., AGU, pp. 95111. 
Usselman, T.M., 1975. Experimental approach to the state of the core: Part I. The liquidus relations of the Fe-rich portion of the Fe-Ni-S system from 30 to $100 \mathrm{~kb}$. American Journal of Science, 275: 278-290.

Utsumi, W. et al., 2002. High-pressure science with a multi-anvil apparatus at SPring-8. Journal of Physics: Condensed Matter, 14: 10497-10504.

Wood, B.J., 1993. Carbon in the core. Earth and Planetary Science Letters, 117: 593-607.

Yang, H. and Secco, A., 1999. Melting boundary of Fe-17\% $\mathrm{Si}$ up to $5.5 \mathrm{GPa}$ and the timing of core formation. Geophysical Research Letters, 26(2): 263-266. 
Table 1: Description of the results of melting experiments.

\begin{tabular}{|c|c|c|c|c|c|}
\hline Exp. & $\mathrm{P}(\mathrm{GPa})$ & $\mathrm{T}_{\text {Sol }}(\mathrm{K})$ & $\mathrm{T}_{\mathrm{Liq}}(\mathrm{K})$ & $\mathrm{X}_{\text {Eut }}(\mathrm{Wt} \%)$ & $\mathrm{N}^{\circ}$ \\
\hline \multicolumn{6}{|c|}{ Mixture of $(\mathrm{Mg}, \mathrm{Fe})_{2} \mathrm{SiO}_{4}$ olivine and $\mathrm{Fe}$} \\
\hline $\mathrm{S} 472^{\$}$ & 15.8 & 1948 & & & 1 \\
\hline S641 $\$$ & 16.3 & 1933 & & & 2 \\
\hline S642\$ & 23.4 & 1963 & & & 3 \\
\hline \multicolumn{5}{|c|}{ S643 $(\alpha, \beta, \varepsilon)$ triple point at [9 GPa, $728 \mathrm{~K}]$} & 4 \\
\hline \multicolumn{6}{|c|}{$\underline{F e}_{0.9} \underline{C}_{0.1}$, mixture of $\mathrm{Fe}_{3} \underline{\mathrm{C}}$ and $\mathrm{Fe}: 2.3 \mathrm{wt} \% \mathrm{C}$} \\
\hline $\mathrm{S} 845 \$$ & 14.0 & 1373 & & & 5 \\
\hline S846 & 20.7 & 1460 & 1573 & & 6 \\
\hline
\end{tabular}

$\underline{\mathrm{Fe}} \underline{0.78}_{\underline{0.7}} \underline{\underline{\mathrm{i}_{0.04}}} \underline{\mathrm{Si}_{0.18}}$ alloy: $10 \mathrm{wt} \% \mathrm{Si}$

$\begin{array}{llllll}\mathrm{S} 849 & 16.9 & 1423 & 1523 & 11.5(2) & 7 \\ \mathrm{~S} 644^{\$} & 22.0 & 1473 & & & 8\end{array}$

$\underline{F e}_{0.85} \underline{O}_{0.15}$, mixture of $\mathrm{Fe}$ and $\mathrm{FeO}: 4.1 \mathrm{wt} \% \mathrm{O}$

$\begin{array}{llllll}\mathrm{S} 1430 & 16.5 & 1473 & 1573 & 9(1) & 9 \\ \mathrm{~S} 1432 & 20.5 & 1523 & 1623 & 10.5(1.0) & 10\end{array}$

$\underline{F e}_{0.9} \underline{S}_{0.1}$, mixture of $F e S$ and $F e: 6 w t \% S$

With no addition

\begin{tabular}{|c|c|c|c|c|c|}
\hline S848 & 18.5 & 1073 & 1523 & $14.5(5)$ & 11 \\
\hline \multicolumn{6}{|c|}{ With addition of $\mathrm{Fe}_{0.98} \mathrm{Si}_{0.02}$} \\
\hline S1431 & 15 & 1023 & 1373 & $20(2)$ & 12 \\
\hline S1434 & 20.6 & 1123 & 1423 & $16(0.5)$ & 13 \\
\hline
\end{tabular}

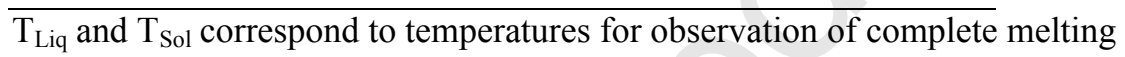
and complete recrystallization, respectively. Contents of light elements in eutectic liquids $\left(\mathrm{X}_{\mathrm{Eut}}\right)$ are derived from Fig. 8 (see text for details).

${ }^{\$} \mathrm{~T}_{\text {Sol }}$ was determined by rapid changes of iron peak intensity

${ }^{\&}$ Sample could not be recovered 
Table 2: EPMA-chemical analyses of recovered samples (wt $\%)$.

\begin{tabular}{|c|c|c|c|c|c|c|}
\hline $\mathrm{N}^{\circ}$ & zone & $\mathrm{O}$ & $\mathrm{Si}$ & $\mathrm{S}$ & $\mathrm{Ni}$ & $\mathrm{Fe}$ \\
\hline \multicolumn{7}{|c|}{$\underline{F e}_{0.9} \underline{C}_{0.1}$} \\
\hline \multirow[t]{2}{*}{$6^{\xi}$} & Depl & $0.05(10)$ & $0.08(2)$ & - & - & $94.7(1)$ \\
\hline & Rich & $0.05(10)$ & $0.10(2)$ & - & - & $92.2(2)$ \\
\hline \multicolumn{7}{|c|}{$\underline{F e_{0.78}} \underline{N i_{0.04}} \underline{S i}_{0.18}$} \\
\hline \multirow[t]{2}{*}{$7^{f}$} & Depl & $0.05(20)$ & $8.6(2)$ & - & $4.8(3)$ & $86.5(3)$ \\
\hline & Rich & $0.2(1)$ & $9.1(4)$ & - & $8.4(3)$ & $82.0(5)$ \\
\hline \multirow[t]{2}{*}{8} & Depl & $0.1(2)$ & $8.9(3)$ & - & $4.9(1)$ & $84.8(3)$ \\
\hline & Rich & $0.2(2)$ & $13.1(4)$ & - & $5.1(5)$ & $81.2(7)$ \\
\hline \multicolumn{7}{|c|}{$\underline{F e}_{0.85} \underline{O}_{0.15}$} \\
\hline $9^{\#}$ & Depl & $0.01(5)$ & $0.14(2)$ & - & - & $99.8(1)$ \\
\hline $10^{\#}$ & Depl & $0.03(5)$ & $0.11(3)$ & - & - & $99.6(1)$ \\
\hline \multicolumn{7}{|c|}{$F e_{0.9} \underline{S}_{0.1}$} \\
\hline \multirow[t]{2}{*}{11} & Depl & $0.20(14)$ & $0.13(4)$ & $0.11(4)$ & - & $99.5(1)$ \\
\hline & Rich & $1.4(4)$ & $0.17(15)$ & $23.5(2.0)$ & - & $78.4(1.5)$ \\
\hline \multirow[t]{2}{*}{12} & Depl & $0.05(10)$ & $0.21(4)$ & $0.04(4)$ & - & $99.5(1)$ \\
\hline & Rich & $0.4(2)$ & $0.5(3)$ & 21.(2) & - & $77 .(2)$ \\
\hline \multirow[t]{2}{*}{13} & Depl & $0.02(5)$ & $0.02(5)$ & $0.01(2)$ & - & $99.6(1)$ \\
\hline & Rich & $0.1(4)$ & $0.08(2)$ & $20 .(2)$ & - & $79 .(2)$ \\
\hline
\end{tabular}

Depl and Rich correspond to sample zones depleted or enriched in light elements, respectively.

$\S$ Carbon content could not be measured. Totals of 95 and 92.6 were obtained after analyses of "solid" (i.e. depleted) or "liquid" (i.e. enriched) parts, respectively.

${ }^{£}$ Some $\mathrm{Fe}_{3} \mathrm{Si}$ grains were also observed in eutectic liquid zone.

\# A phase with FeO stoichiometry was observed. 


\section{FigURE CAPTIONS}

Figure 1: Experimental assemblage used for the in situ experiments performed at the BL04B1 beamline of the SPring8 synchrotron. The thermocouple runs just aside the sample chamber at equal distances between the two $\mathrm{LaCrO}_{3}$ sheet furnaces. Are not shown in this figure two additional $\mathrm{MgO}$ spacers, located at the front and bottom, which use is to complete the octahedral shape of the assemblage. Once inserted in the press, the $\mathrm{Al}_{2} \mathrm{O}_{3}$ tube containing the sample and the pressure medium is found parallel to the gap between two anvils.

Figure 2: The iron phase diagram as compiled from previous works (Boehler, 1986; Funamori et al., 1996). We report the P-T conditions experienced by the different samples used in this study. Data labels refer to the samples, as reported in Table 1. The $\varepsilon$-hcp to $\gamma$-fcc phase transition in pure iron (green circles with white numbers) is observed at similar P-T conditions than reported in the literature, which insure no systematic error in our temperature measurement (see text for data labelled "6" and "11").

Figure 3: X-ray diffraction patterns recorded for the $\mathrm{Fe}_{0.9} \mathrm{C}_{0.1}$ sample at a pressure of 20.7 GPa and for temperatures at 1173 and $1573 \mathrm{~K}$. The dots and the 2 solid lines represent experimental data, and fits of profile and background intensities, respectively. Diffraction lines are explained by the presence of $\mathrm{Al}_{2} \mathrm{O}_{3}$ (sample container), $\mathrm{SiO}_{2}$ (mixed with the sample), traces of $\mathrm{W}$ (thermocouple), and $\gamma$-fcc iron at $1173 \mathrm{~K}$. The clear difference between the two backgrounds is due to the diffuse $\mathrm{x}$-ray scattering of the liquid iron-alloy at $1573 \mathrm{~K}$.

Figure 4: Experimental (bottom) and modelled X-ray diffusion bands using bcc, hcp, and fcc models for the local structure in liquid Fe-C alloy (Exp N 6 at $20.7 \mathrm{GPa}$ and $1573 \mathrm{~K}$ ). The diffusion band is well explained by the presence of a liquid Fe-alloy with the bcc structure.

Figure 5: Selected backgrounds and diffuse $x$-ray scattering of the patterns recorded during the cooling of (a) $\mathrm{Fe}_{0.9} \mathrm{C}_{0.1}$, (b) $\mathrm{Fe}_{0.78} \mathrm{Ni}_{0.04} \mathrm{~S}_{0.18}$, (c) $\mathrm{Fe}_{0.9} \mathrm{O}_{0.1}$ and (d) $\mathrm{Fe}_{0.9} \mathrm{~S}_{0.1}$ samples at 20.7, 16.9, 20.5 and 18.5 GPa, respectively. The bottom curve in each figures correspond to solid samples. We observed maximum intensities at the highest temperatures, when the sample is completely molten. The degree of partial melting, correlated with the intensity of the diffuse band, is observed to decrease with decreasing temperature until the background reaches the classical shape of the Compton diffusion. Note a second diffusion peak observed at $\sim 68 \mathrm{keV}$ 
and $\sim 66 \mathrm{keV}$ for the $\mathrm{Fe}_{0.9} \mathrm{O}_{0.1}$ and $\mathrm{Fe}_{0.9} \mathrm{~S}_{0.1}$ samples, respectively. The diffraction angle was different for each set of figures.

Figure 6: Degree of partial melting observed as a function of decreasing temperature, as extracted from the intensity of the diffuse x-ray scattering presented in Fig. 5. This figure is constructed based on the fact that $100 \%$ partial melting is achieved at the temperature where the intensity of the diffuse X-ray band of molten iron becomes constant on further temperature increase.

Figure 7: Scanning electron microphotograph of typical areas in iron alloys recovered from experiments at high pressure and temperature. The darkest areas represent the stishovite matrix in all samples. Zoning of the metallic grains is clearly visible. Brightness increases with atomic number i.e. with decreasing amount of light elements. (a) C-enriched (dark) or depleted zones (bright). Darker spots correspond to C-deposits due to SEM beam; (b) quenched eutectic liquid (bright) and eutectic solid (dark) in the Fe-Ni-Si system. The quenched liquid appears brighter because it shows a slightly higher Ni-content; (c) $\mathrm{Fe}_{1-\varepsilon} \mathrm{O}_{\varepsilon}$ (bright) and $\mathrm{FeO}$ (dark); (d) $\mathrm{Fe}_{1-\varepsilon} \mathrm{S}_{\varepsilon}$ (bright) and $\mathrm{Fe}_{2} \mathrm{~S}$ (dark). The eutectic liquid displays an eutectoid texture consisting of an intimate mixture of the two phases S-poor solid and $\mathrm{Fe}_{2} \mathrm{~S}$.

Figure 8: Frames A, B, C, D, E and F correspond to experiments $\mathrm{n}^{\circ}$ 7, 12, 13, 11, 9 and 10, respectively. The high-pressure melting diagrams are drawn thanks to the knowledge of (1) eutectic temperature and liquidus temperature (Table 1), (2) chemical composition of the eutectic-solid (Table 2), and (3) degree of iron-alloy partial melting as a function of temperature (Figs. 6). Melting temperatures of pure iron are taken from a previous works (Boehler, 1986; Shen et al., 1993).

Figure 9: Change in eutectic temperature with pressure in the Fe-S system. The pressure evolution is affected by occurrence of $\mathrm{Fe}_{3} \mathrm{~S}_{2}$ and $\mathrm{Fe}_{3} \mathrm{~S}$ solid phases at 14 and $21 \mathrm{GPa}$, respectively (Fei et al., 1997; Sherman, 1995). 


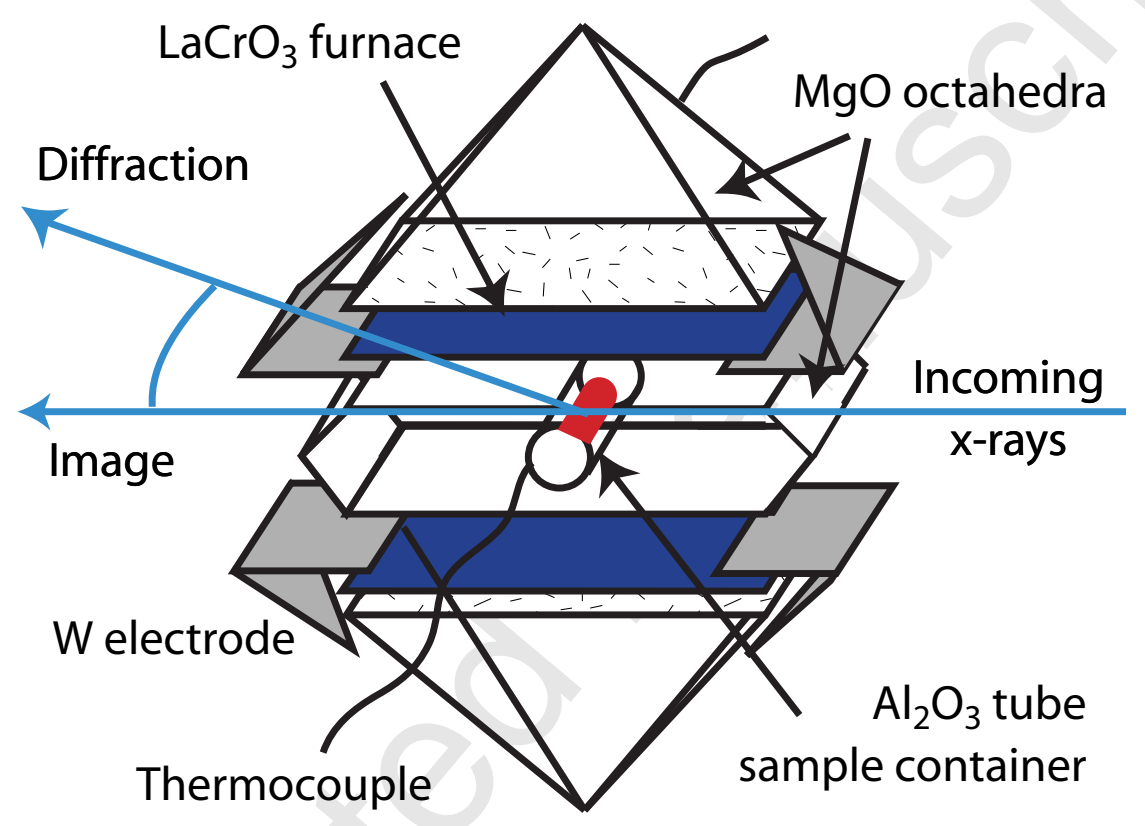

Figure 1

Page 26 of 34 


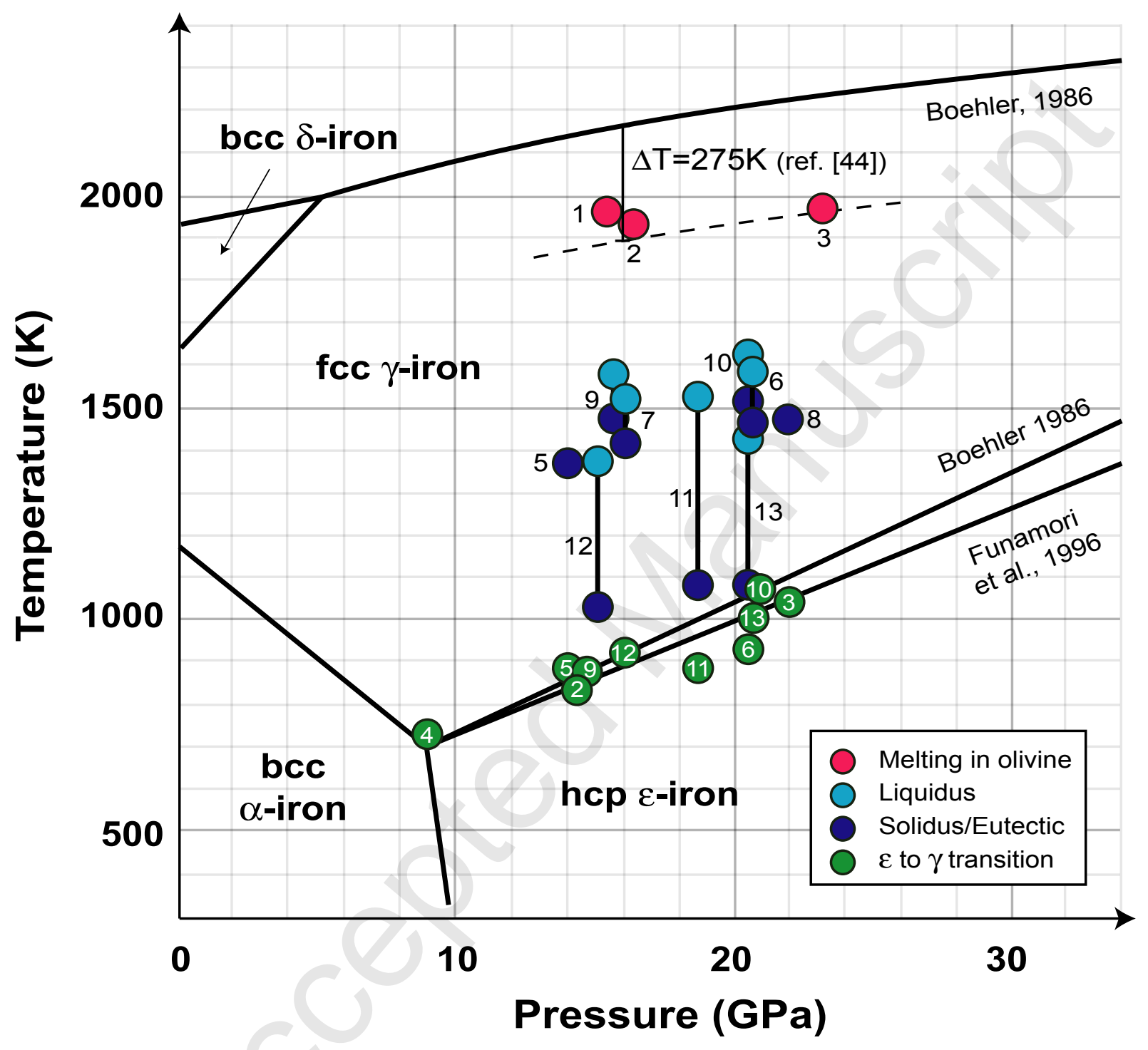

Figure 2 


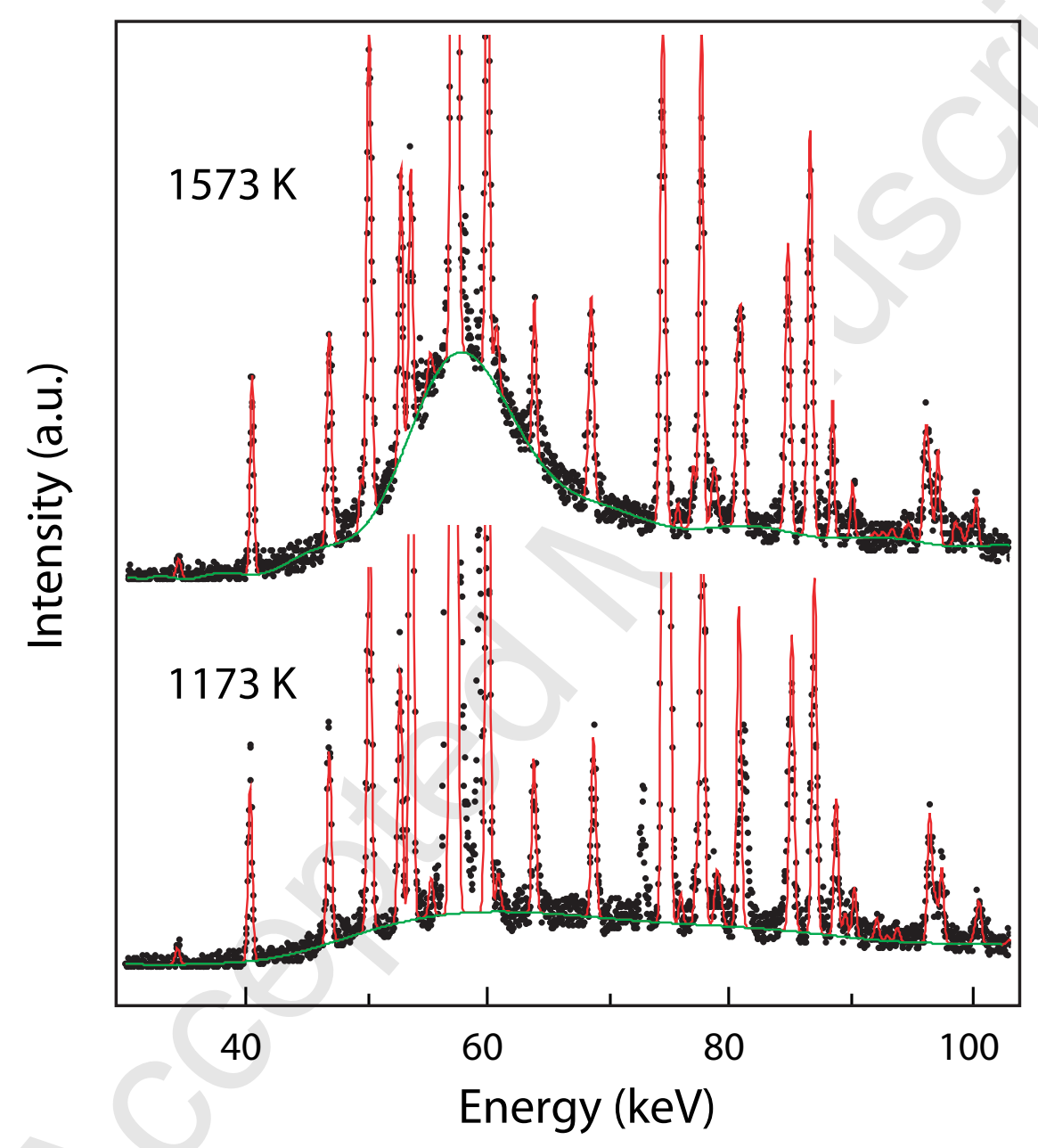

Figure 3 


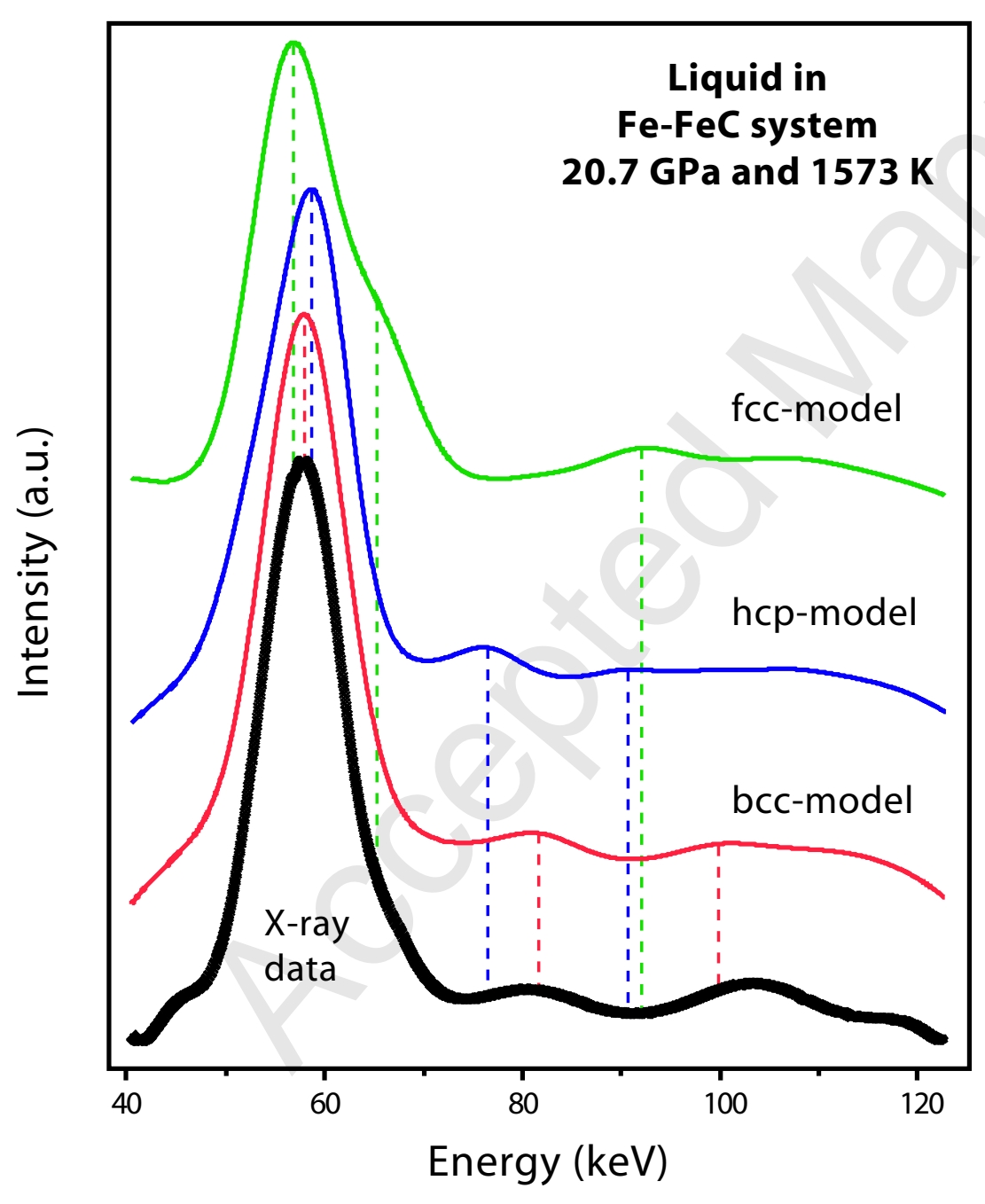

Page 29 of 34

Figure 4 

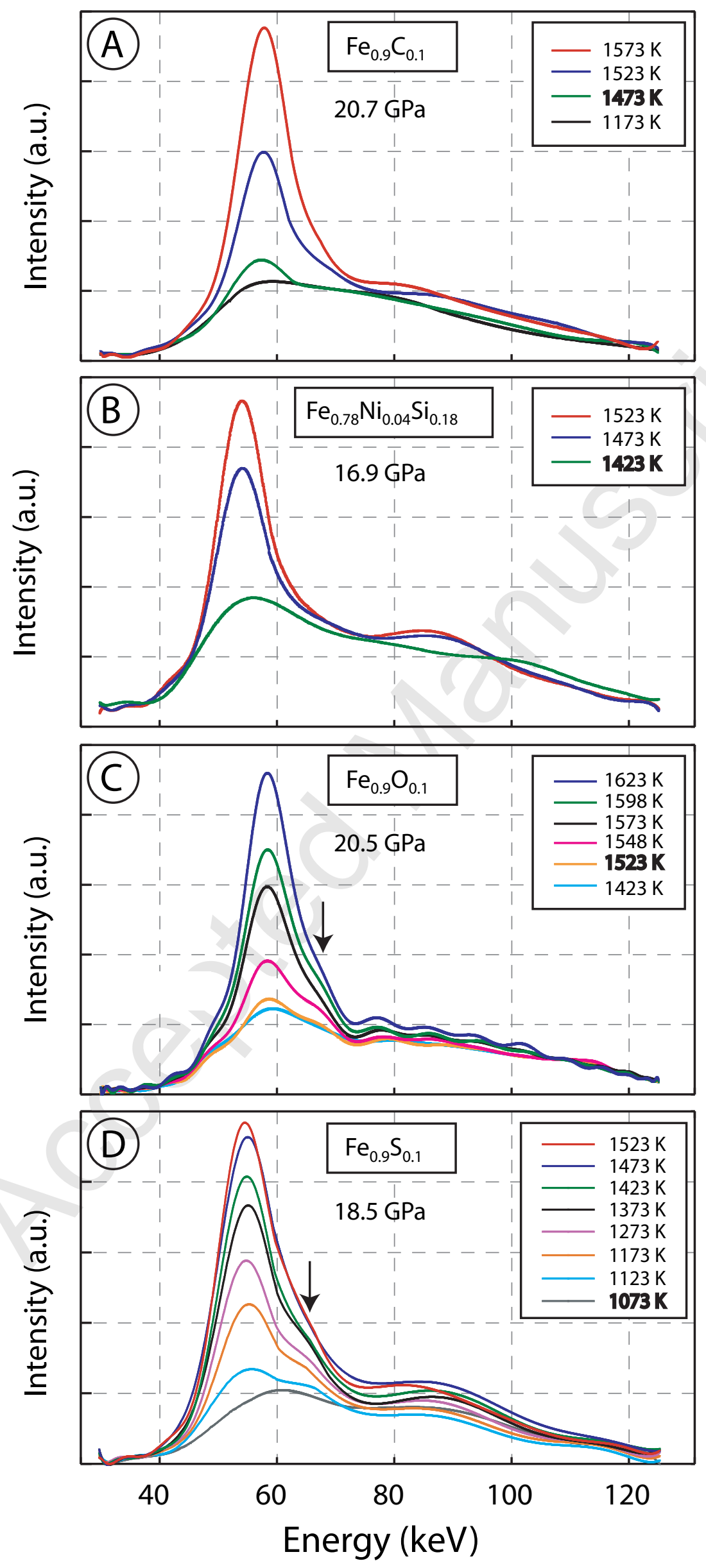

Figure 5

Page 30 of 34 


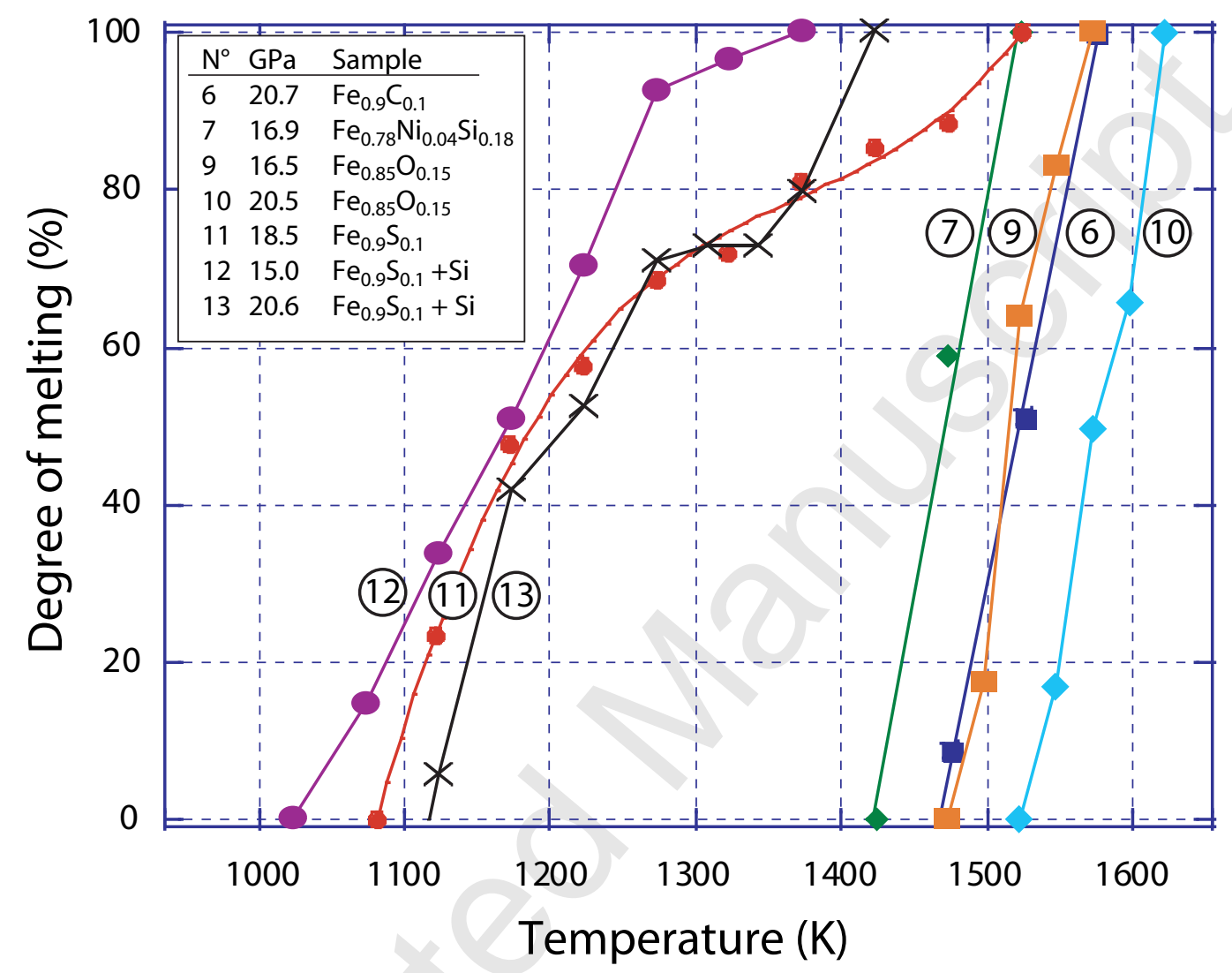

Figure 6 

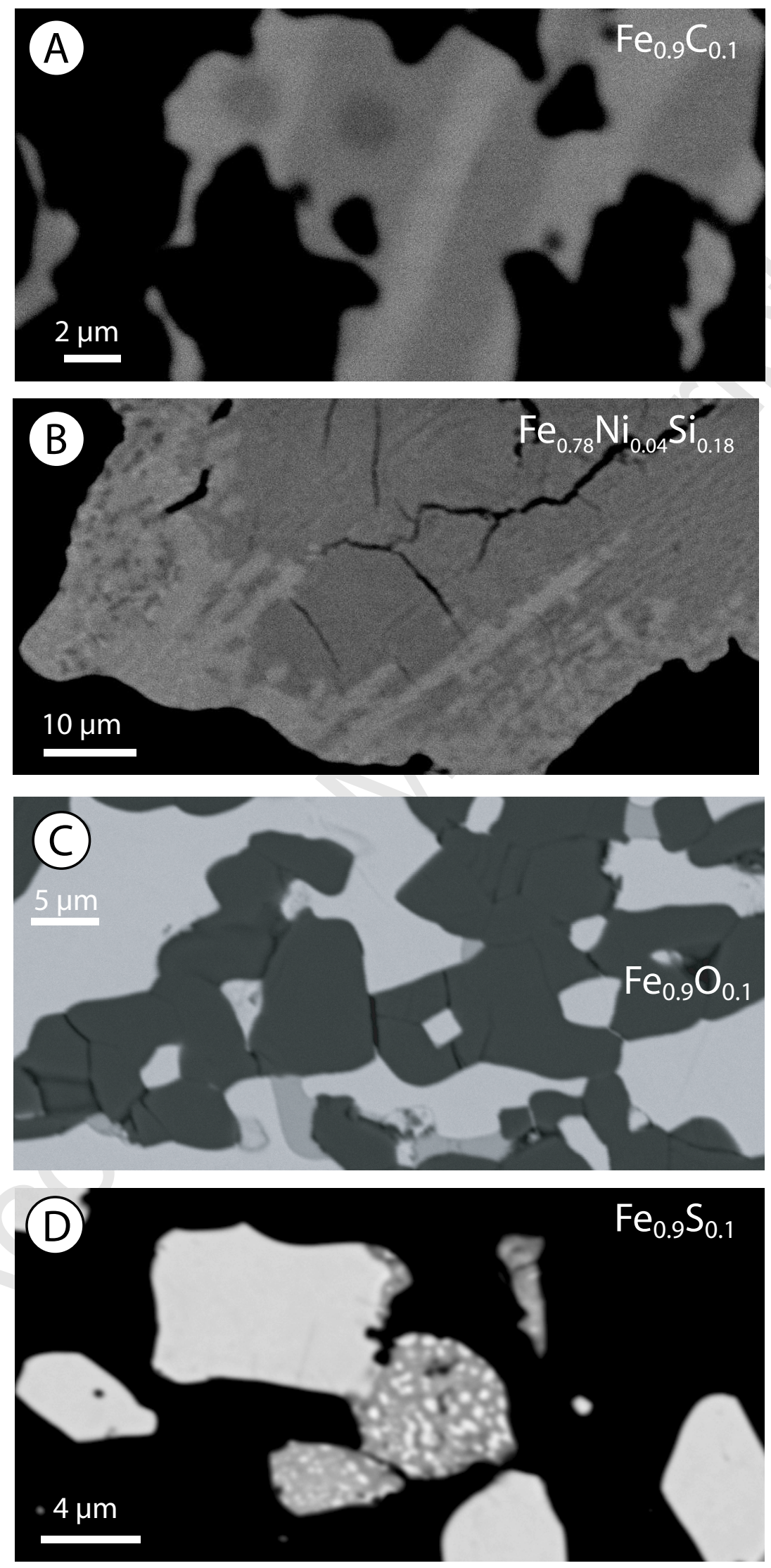

Figure 77 

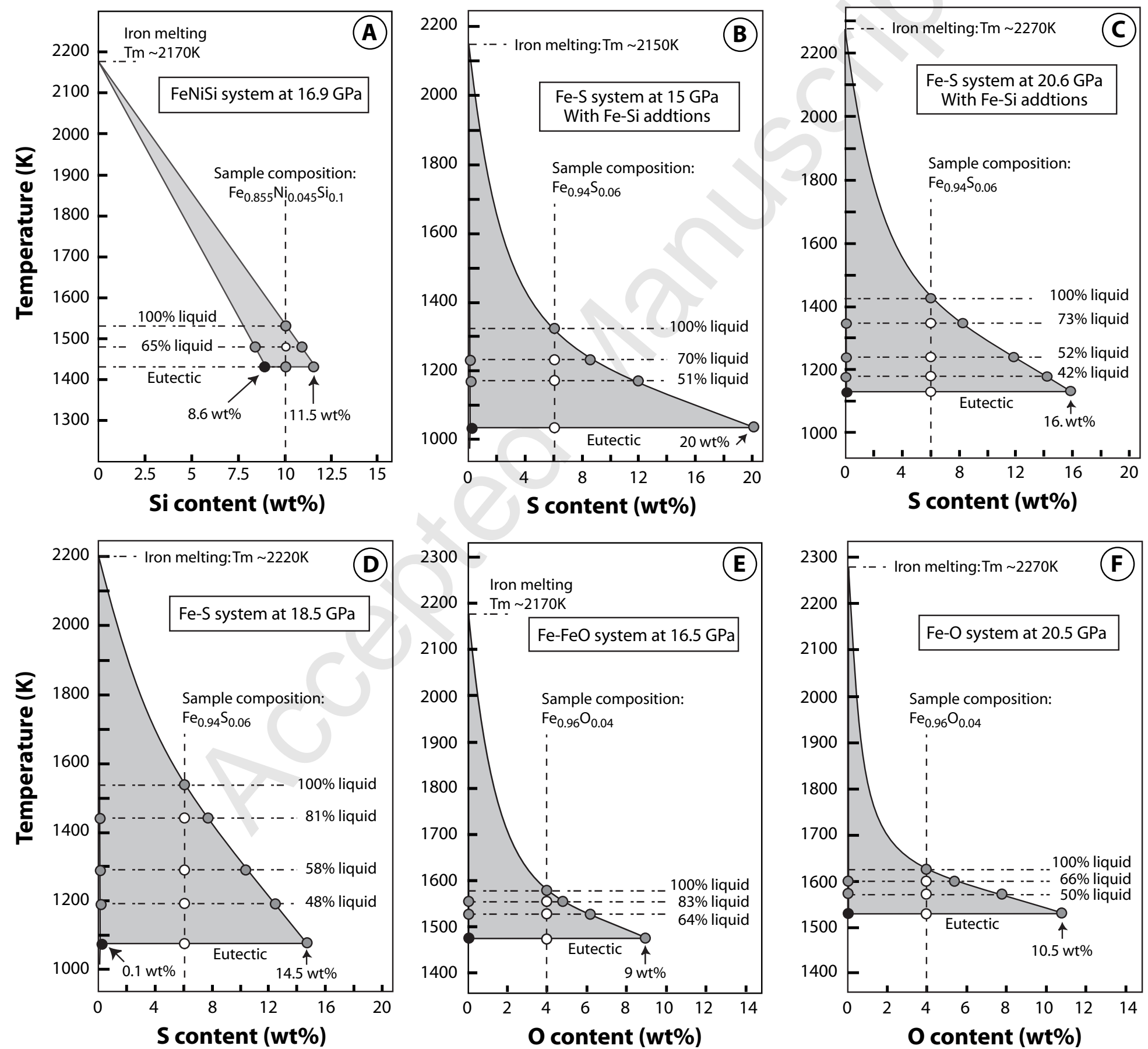

Figureage 33 of 34 


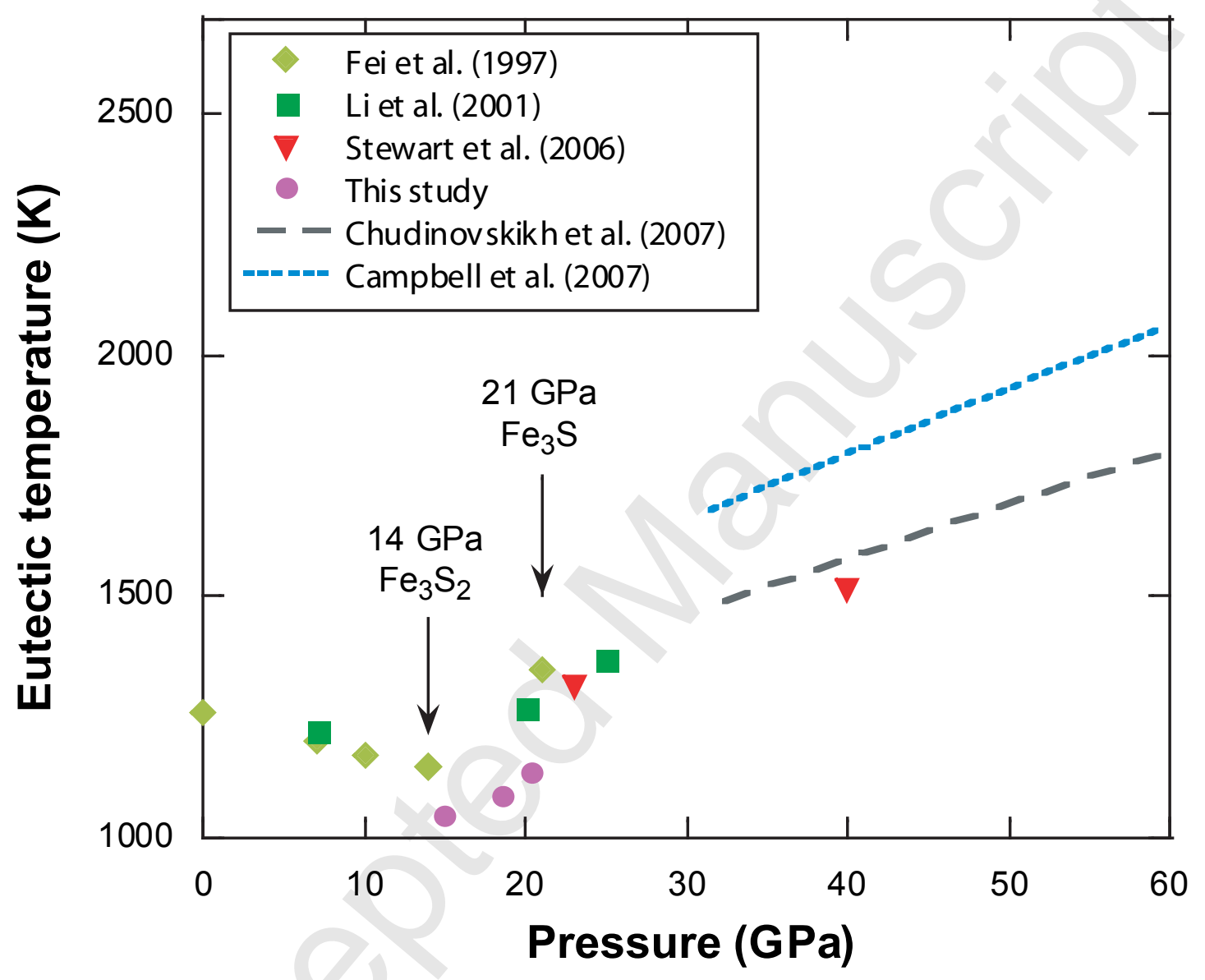

Figure 9 